\title{
WestVirginiaUniversity
}

THE RESEARCH REPOSITORY @ WVU

Graduate Theses, Dissertations, and Problem Reports

2012

\section{Production Decline Behavior of Shale Gas Reservoirs}

Zahra Razzaghpanah

West Virginia University

Follow this and additional works at: https://researchrepository.wvu.edu/etd

\section{Recommended Citation}

Razzaghpanah, Zahra, "Production Decline Behavior of Shale Gas Reservoirs" (2012). Graduate Theses, Dissertations, and Problem Reports. 4912.

https://researchrepository.wvu.edu/etd/4912

This Thesis is protected by copyright and/or related rights. It has been brought to you by the The Research Repository @ WVU with permission from the rights-holder(s). You are free to use this Thesis in any way that is permitted by the copyright and related rights legislation that applies to your use. For other uses you must obtain permission from the rights-holder(s) directly, unless additional rights are indicated by a Creative Commons license in the record and/ or on the work itself. This Thesis has been accepted for inclusion in WVU Graduate Theses, Dissertations, and Problem Reports collection by an authorized administrator of The Research Repository @ WVU. For more information, please contact researchrepository@mail.wvu.edu. 


\title{
Production Decline Behavior of Shale Gas Reservoirs
}

\author{
Zahra Razzaghpanah
}

Thesis submitted to the Statler College of Engineering at West Virginia University

in partial fulfillment of the requirements for the degree of

\section{Master of Science}

in

Petroleum \& Natural Gas Engineering

Kashy Aminian, Ph.D., Chair

Samuel Ameri, M.S.

Daniel E. Della-Giustina, Ph.D.

Department of Petroleum \& Natural Gas Engineering

Morgantown, West Virginia

2012

Keywords: Decline Curve

Analysis, Shale Gas Reservoir, Horizontal Wells, Adsorbed Gas

Copyright 2012 Zahra Razzaghpanah 


\section{ABSTRACT \\ Production Decline Behavior of Shale Gas Reservoirs}

Zahra Razzaghpanah

The rise in global demand for energy leads oil and gas industry to enhance and develop newer techniques and technologies that produce more oil and gas from resources. Unconventional gas resources comprise a very important share of the domestic natural gas resource base and offer tremendous potential for future reserve and production growth. One of the most important issues associated with shale gas reservoirs is to have an accurate and reliable estimation of the reserves and ultimate recovery. The purpose of this research is to compare different decline curve analysis techniques, it is also to provide a more reliable method for production forecast and reserve estimate for hydraulically fractured horizontal wells producing from gas shale reservoirs. In this study, first, long-term production performance for a variety of well-reservoir systems, including different fracture stages and with and without adsorbed gas cases were simulated. Subsequently, different decline analysis methods were evaluated in employed to predict future performance using the early part of the simulated production history These methods-include Conventional Decline Curve Analysis, Weibull Model, and the Power Law Method. The evaluation task was accomplished through quantitative comparison of production forecast results from the decline analysis with the simulated production history. The Power Law Method provided reliable prediction when number of hydraulic fractures was low. However, the Conventional Decline Curve Analysis was found to provide more reliable results in estimating reserves and analyzing production in the cases where the number of hydraulic fracture was high. 


\section{DEDICATION}

Dedicated to my dear God, without Him guiding my every step, nothing would be possible for me.

Dedicated to my loving, caring and industrious parents, who have always been making sacrifices along the way to help me achieve my goals 


\section{ACKNOWLEDGEMENTS}

I would like to express my heartfelt deep appreciation to my advisor Dr. Kashy Aminian for his mentoring, encouragement throughout this project. His knowledge and wisdom were my resources during the course of this work. His contributions are numerous and valuable. I would like to thank the other committee members, Dr. Ameri and Dr. Della-Giustina For their continuous support.I would like to express my gratitude to my dear Friend Soheil Razmyar for being always there and providing unlimited support idea and assistance throughout this project. Finally, I cannot express enough love and appreciation for my parents for their support. Everything I have achieved is because of them. 


\section{TABLE OF CONTENTS}

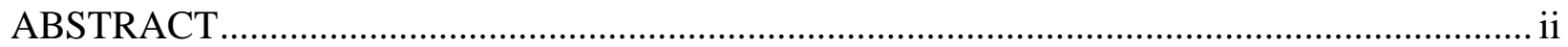

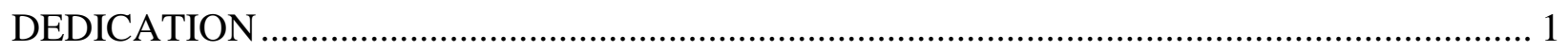

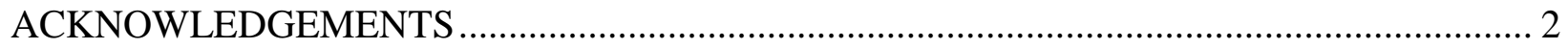

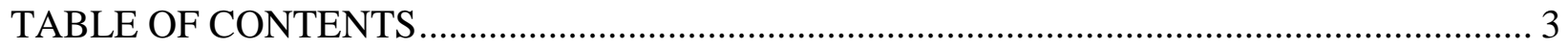

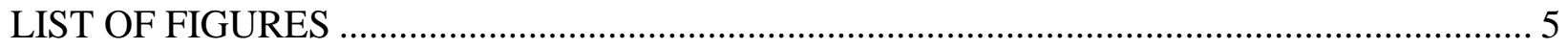

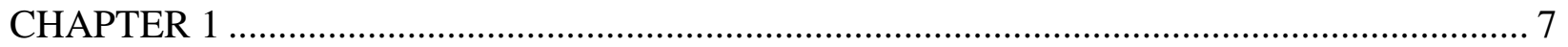

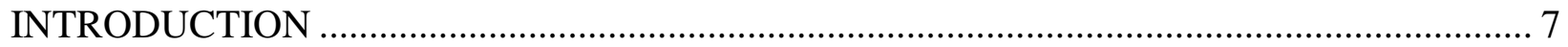

1.1 Unconventional Reservoir Systems — Overview ........................................................ 7

1.2 Production Technologies in Unconventional Reservoirs ............................................ 10

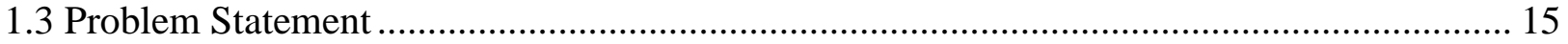

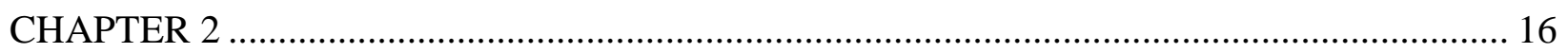

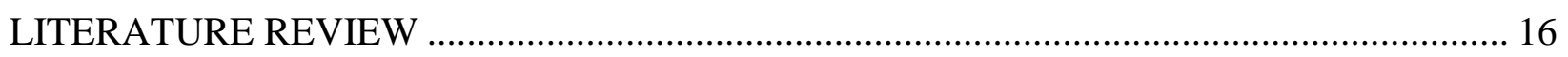

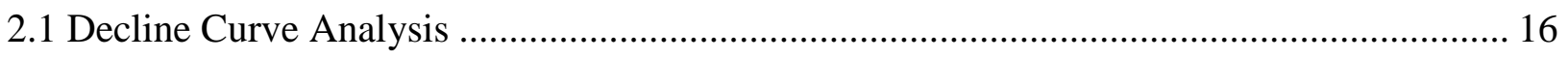

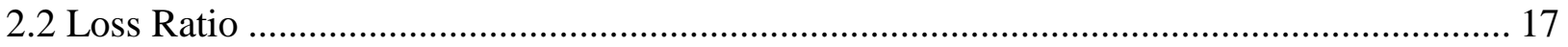

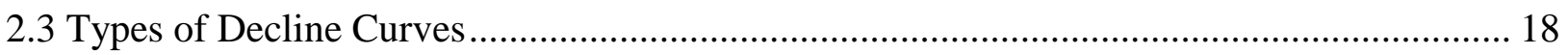

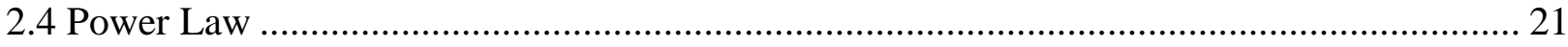

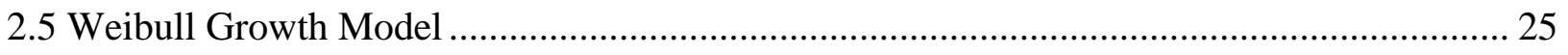

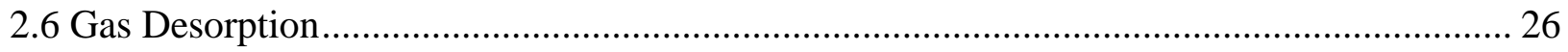

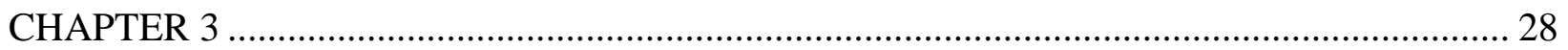

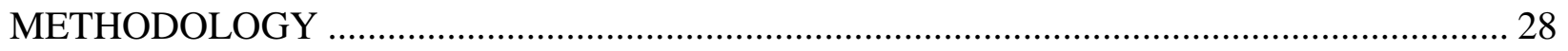

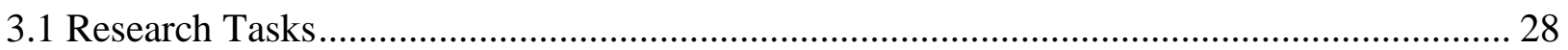

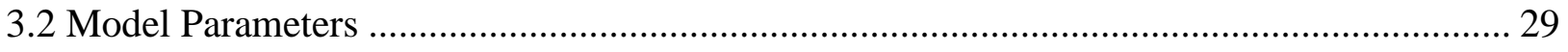

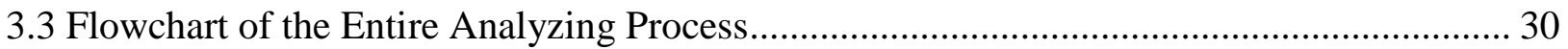

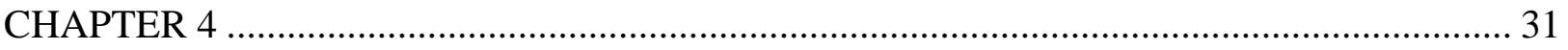




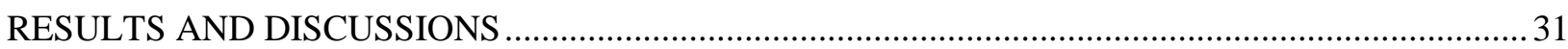

4.1 Case 1 - Horizontal well with 7 hydraulic fractures including gas adsorption ................... 31

4.2 Case 2 - Horizontal well with 7 hydraulic fractures excluding gas adsorption................... 36

4.3 Case 3 - Horizontal well with 13 hydraulic fractures including gas adsorption ................. 41

4.4 Case 4 - Horizontal well with 13 Fractures excluding Desorbed Gas............................... 46

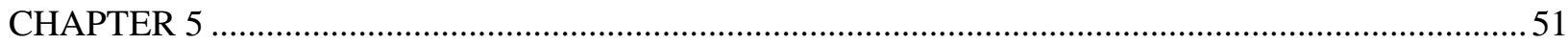

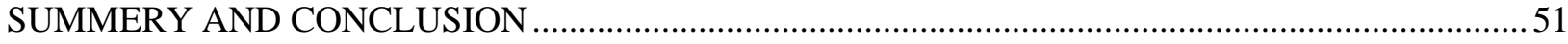

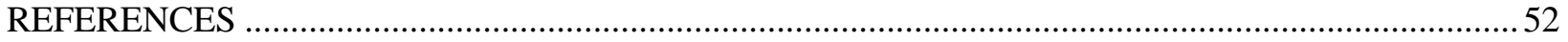




\section{LIST OF FIGURES}

Figure 1. Resource Triangle for classification of hydrocarbon resources [Masters 1979, Holditch 2006, Ilk 2010] 7

Figure 2. United States Shale Plays [www.pacwestcp.com] ............................................. 8

Figure 3, Hydraulic fracturing process [Tschirhart 2007] ............................................... 11

Figure 4. Horizontal drilling increases the length of pay zone [Geology.com]....................... 13

Figure 5. Horizontal well with multi stage fractures [www.geology.com] ............................. 14

Figure 6. Different types of Decline Curves [www.fekete.com] ….................................... 20

Figure 7. Arps' rate-time and cumulative-time relations (adapted from Blasingame and Rushing 2005). 20

Figure 8. A Langmuir Isotherm Curve: Gas Content plotted against Pressure [Adekoya et al 2009] 27

Figure 9. Model Parameters [F. Belyadi, A. Mashayekhi, K. Aminian, and S. Ameri 2012] ...... 29

Figure 10, Flowchart of the entire analysis process ....................................................... 30

Figure 11. 7 fractures with adsorption simulated data Curve vs. Power Law model match ........ 32

Figure 12. Extrapolation for the rest 16 years of production ( 7 fractures with adsorption) ......... 33

Figure 13. 7 fractures with adsorption simulated data Curve vs. Conventional Decline match... 34

Figure 14. Extrapolation for the rest 16 years of production ( 7 fractures with adsorption) ......... 35

Figure 15. 7 fractures without adsorption simulated data Curve vs. Power Law model match ... 37

Figure 16. Extrapolation for the rest 16 years of production ( 7 fractures without adsorption) .... 38

Figure 17. 7 fractures without adsorption simulated data Curve vs. Conventional Decline match 39

Figure 18. Extrapolation for the rest 16 years of production ( 7 fractures without adsorption) .... 40 
Figure 19. 13 fractures with adsorption simulated data Curve vs. Power Law model match ...... 42

Figure 20. Extrapolation for the rest 16 years of production (13 fractures with adsorption) ....... 43

Figure 21.13 fractures with adsorption simulated data Curve vs. Conventional Decline match.. 44

Figure 22. Extrapolation for the rest 16 years of production (13 fractures with adsorption) ....... 45

Figure 23. 13 fractures without adsorption simulated data Curve vs. Power Law match ........... 47

Figure 24. Extrapolation for the rest 16 years of production (13 fractures without adsorption) .. 48

Figure 25. 13 fractures without adsorption simulated data Curve vs. Conventional Decline match

Figure 26. Extrapolation for the rest 16 years of production (13 fractures without adsorption) .. 50 


\section{CHAPTER 1}

\section{INTRODUCTION}

1.1 Unconventional Reservoir Systems - Overview

Based on the reservoirs rock type and hydrocarbon properties hydrocarbon deposits are either conventional or unconventional reservoirs. Conventional reservoirs are known as the highly permeable oil and gas reservoirs which can produce at almost high rates relying on reservoirs own initial pressure. On the other hand, unconventional reservoirs such as tight gas sands, coal bed gas, shale gas, and tight oil refers to formations with the permeability on the micro-Darcy scale that makes it too complicated and difficult to produce despite their huge amount of reserves inside.[Ilk, 2008]

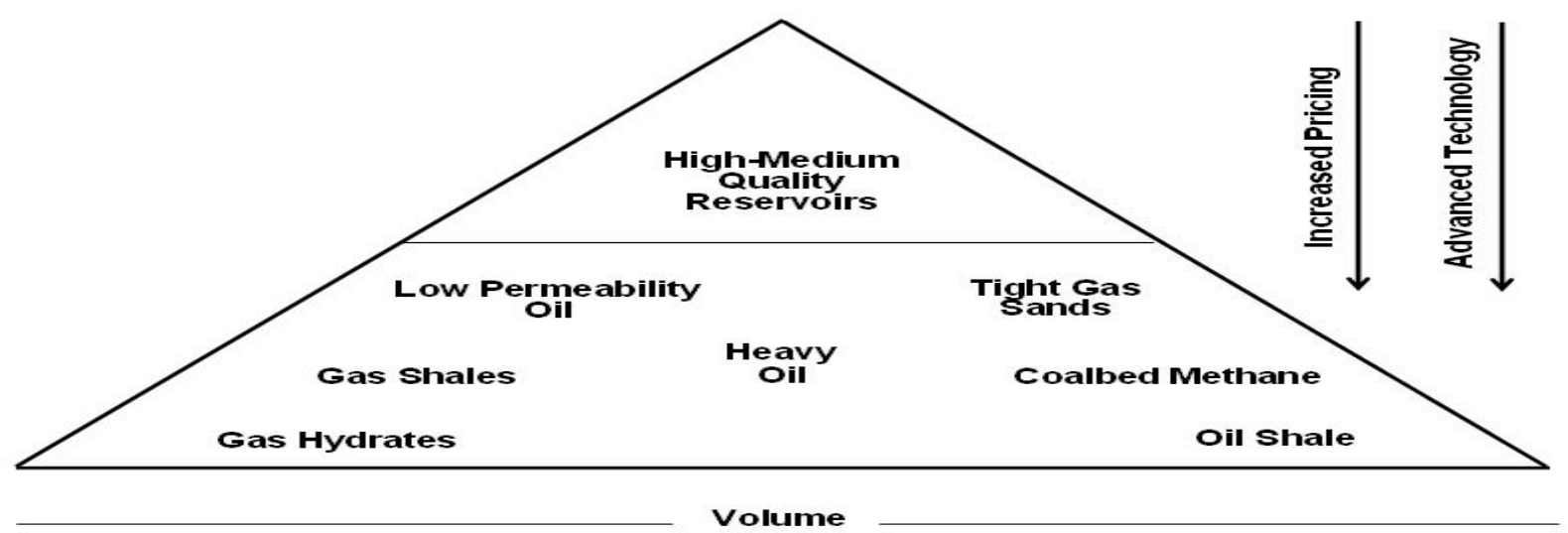

Figure 1. Resource Triangle for classification of hydrocarbon resources

[Masters 1979, Holditch 2006, Ilk 2010] 
Recent advances in oil and gas industry has made the exploitation of unconventional reservoirs more economically profitable. Thus the production from unconventional reservoirs is considered as the major source of energy supply of the United States, since almost $13 \%$ of the world's unconventional recourses are located in the United States.

The major tight gas plays in the US include Pinedale/Jonah Fields (Green River Basin), Mesaverde/Williams Fork Formations (Piceance and Uinta Basins), and Bossier/Cotton Valley (East Texas Basin)[NETL 2010]. Also the most important shale gas plays found in the US are Barnett Shale, Fayetteville Shale, Woodford Shale, Haynesville Shale, and Marcellus Shale.

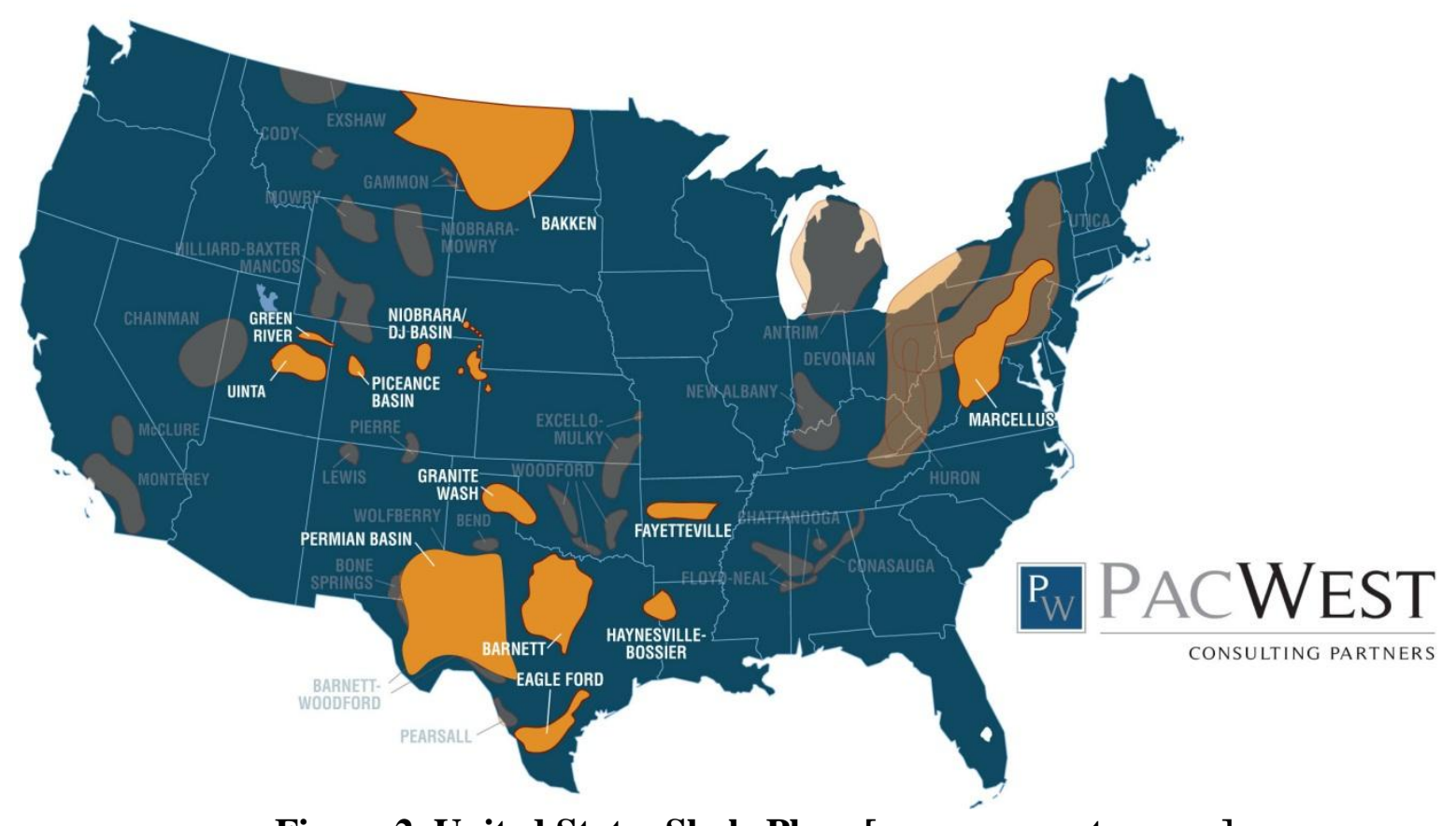

Figure 2. United States Shale Plays [www.pacwestcp.com]. 
From a geological perspective, unconventional reservoirs are distinct from conventional reservoirs [Law and Curtis 2002]. While in Conventional reservoirs hydrocarbons are accumulated in structural and/or stratigraphic traps, unconventional reservoir systems can be considered as continuous accumulations. Accumulation of hydrocarbons in unconventional reservoirs can be widespread in a large volume of rock free of structural and stratigraphic traps. As a result, the field of interest can be extensive with a large in-place fluid volume and low recovery factor [Schmoker 2002]. This causes too much uncertainty in estimating reserve in unconventional reservoirs using conventional reserve estimation methods which means the analysis of well performance data for more accurate reserves assessment will extremely be important.

Unconventional reservoir systems exhibit unique flow behavior due to low permeability caused by depositional and digenetic issues, and reservoir heterogeneity governed by deposition and digenetic events [Blasingame 2008]. Unconventional reservoirs are known as very fine grain rock texture, where gas storage and flow characteristics are exclusively tied to nano-scale pore throat and pore size distribution. Specifically in unconventional reservoirs the gas storage can be seen on the surface areas of the organic and clay content by sorption phenomena. 
Shale gas reservoir systems are comprised of fine-grained, clay and organic carbon rich rocks this can be both gas source and reservoir rock components of the petroleum system [Martini et al. 1998]. Gas can be dissolved in Kerogen, as sorbet hydrocarbon on the surface area, and as free gas in fracture [Schettler and Parmely, 1991]. Trapping mechanisms are not obvious, and gas saturations cover large geographic areas [Roen, 1993].

\subsection{Production Technologies in Unconventional Reservoirs}

Since Low Permeability nature of the unconventional reservoirs makes production of these reservoirs not economical it is mandatory to use technological stimulation methods discussed below to intervene the reservoir rock for economical production.

Hydraulic fracturing allows the opening of a large surface area of the reservoir rock to enhance the fluid flow to the wellbore. Polymer gel fluids with large proppant concentrations were utilized in early hydraulic fracture treatments in order to create long, highly conductive fractures [Rushing and Sullivan 2003]. Gel fluids also bring up several issues such as fracture damage, high net fracturing pressures and difficult clean-up process. All these make the cost of making stimulation less effective and eventually, uneconomic. Thus, water fracturing technology was developed as a lower cost alternative for hydraulic fracturing. 


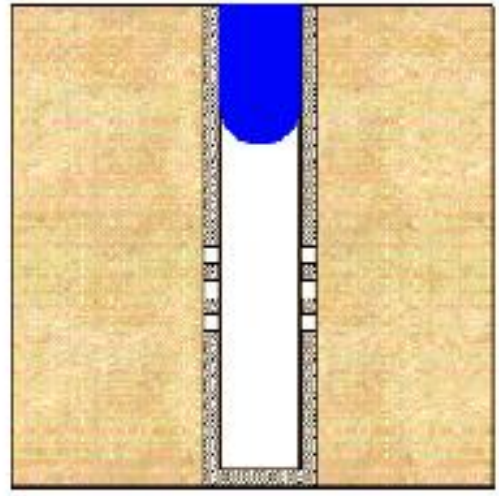

a. Fluid is pumped down well.

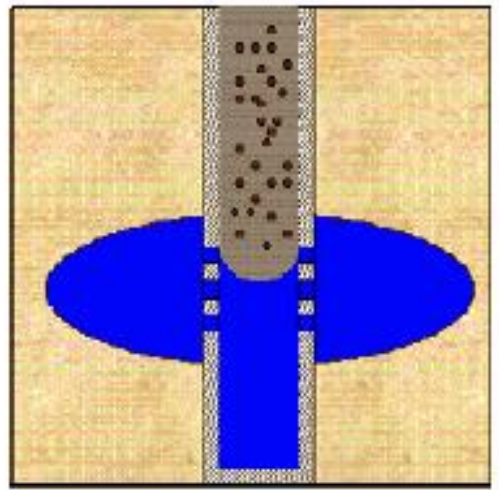

d. Proppant is transported with viscous fluid into fracture.

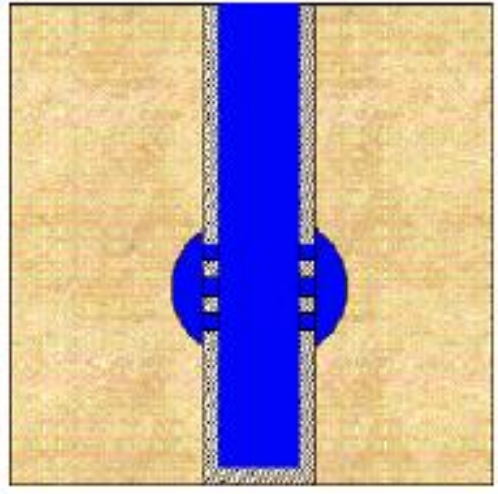

b. Hydraulic pressure of fluid initiates a fracture in the reservoir.

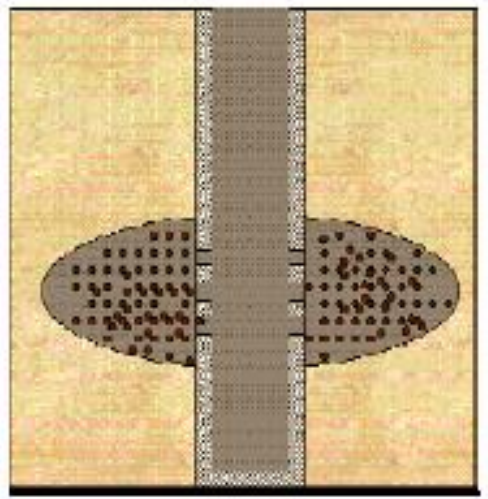

e. Viscous fluid uniformly transports fluid deeply into the fracture.

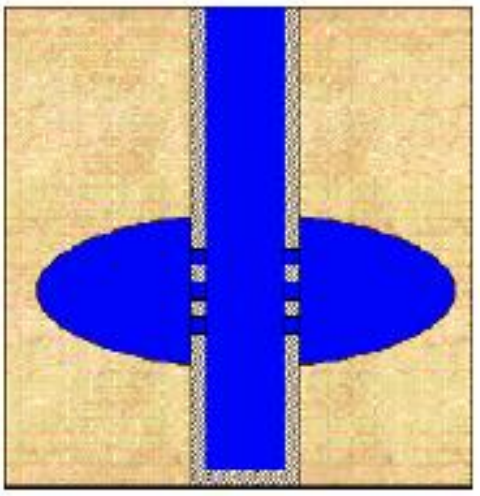

c. Fracture begins propagating into reservoir.

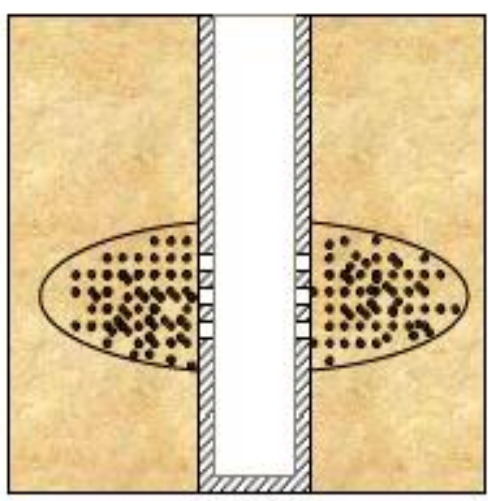

f. Viscous fluid breaks and is allowed to flow back out of well. The formation closes upon proppants resulting in a long conductive fracture.

Figure 3, Hydraulic fracturing process [Tschirhart 2007]. 
Water fracturing technology (water-fracs) is a fracturing process used to achieve optimum production by injecting large volume of water with little or no proppant to create the sufficient fracture geometry and conductivity. Many different observations conclude that water-fracs can indeed generate better production responses and even create longer fracture lengths [Mayerhofer et al. 1997; Mayerhofer and Meehan 1998; Walker et al. 1998]. Lower cost, reduced gel fluid damage, lower viscosity are the advantages that have made water-fracs more favorable for stimulating very low permeability shale gas reservoirs. In fact, higher pumping rates allow the opening of fracture networks in shale gas reservoirs [Palisch, Vincent, and Handren 2008].On the other hand, issues related with poor proppant transport and low fracture conductivity due to none or low proppant concentrations [Fredd et al. 2001] could hinder the success of water-fracs process. Since the last decade Water-fracs have been the widely used stimulation technology in shale gas reservoirs

Matrix Acidizing is a well stimulation technique based on injecting acid solution (HCL, mixture of HCL \& HF) into a formation to dissolve some minerals present in the reservoir to facilitate the fluid flow path from reservoir to the wellbore.

Horizontal drilling with multi-stage fracture treatment completion has been employed in industry for the exploitation of the unconventional reservoirs. More reservoir rock surface area is exposed with horizontal wells, and creation of multiple hydraulic fractures results in significant increases in production [Ilk et al. 2010]. 
Horizontal well is deviation of a vertical hole to horizontal direction to not only let the well penetrate a maximum number of vertical rock fractures but also to produce a well with a very long "pay zone" that reaches more of a gas-bearing rock. This is because more of the natural fractures in shale reservoir are vertical fractures and vertical wells can barely intersect small number of them. According to the observations made the productivity of the horizontal wells are between 2 to 5 times or than vertical wells in shale reservoirs, Which means a horizontal well can produce with about half or one third of the reservoir pressure required for vertical well to have an economic production.

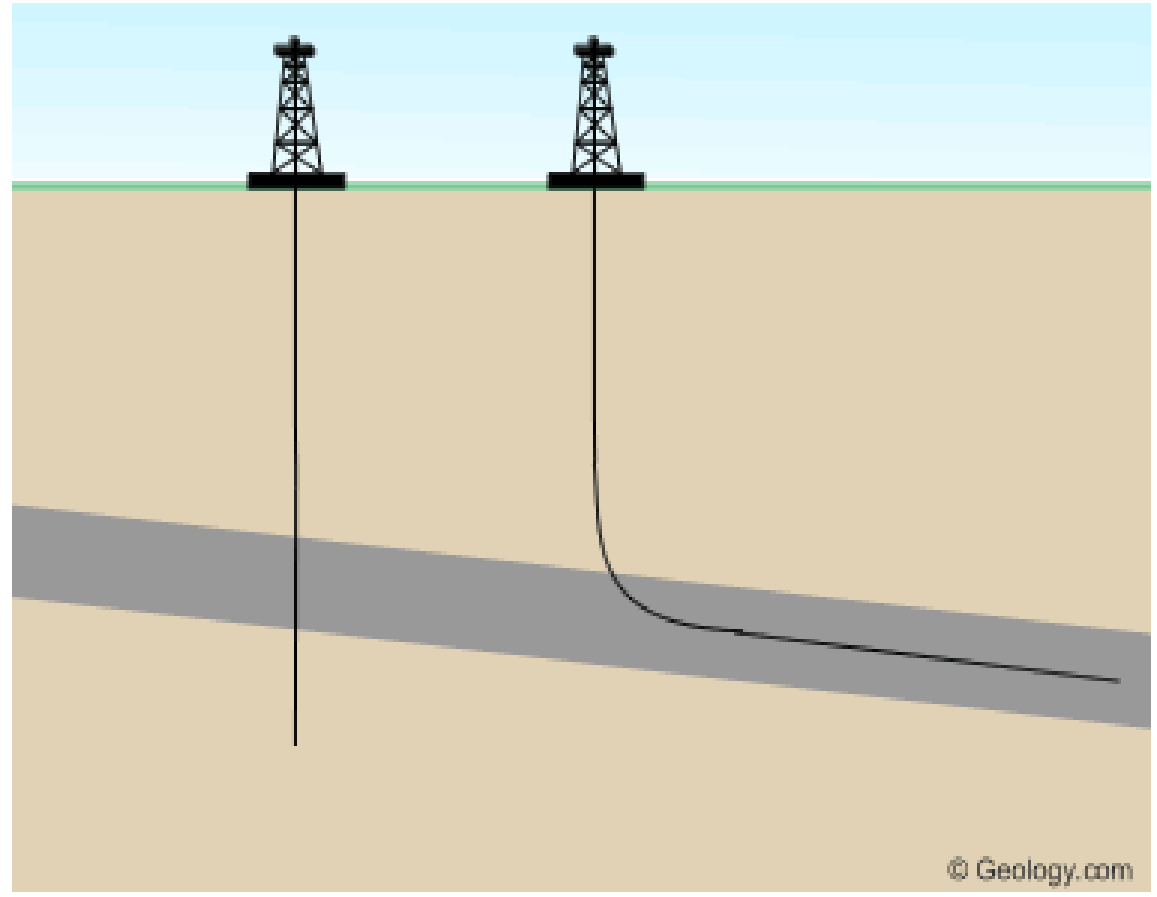

Figure 4. Horizontal drilling increases the length of pay zone [Geology.com] 
Hydraulic fracture treatment activates the existing natural fractures creating a fracture network which is a major factor effecting well performance as the larger fracture networks are, the better well performance would be. Based on Mayerhofer et al. (2006)'s numerical simulations fracture network size, fracture density, and fracture conductivity are the key factors for production. Also stimulated reservoir volume is directly related to the fracture network size.[Ilk et el 2008]

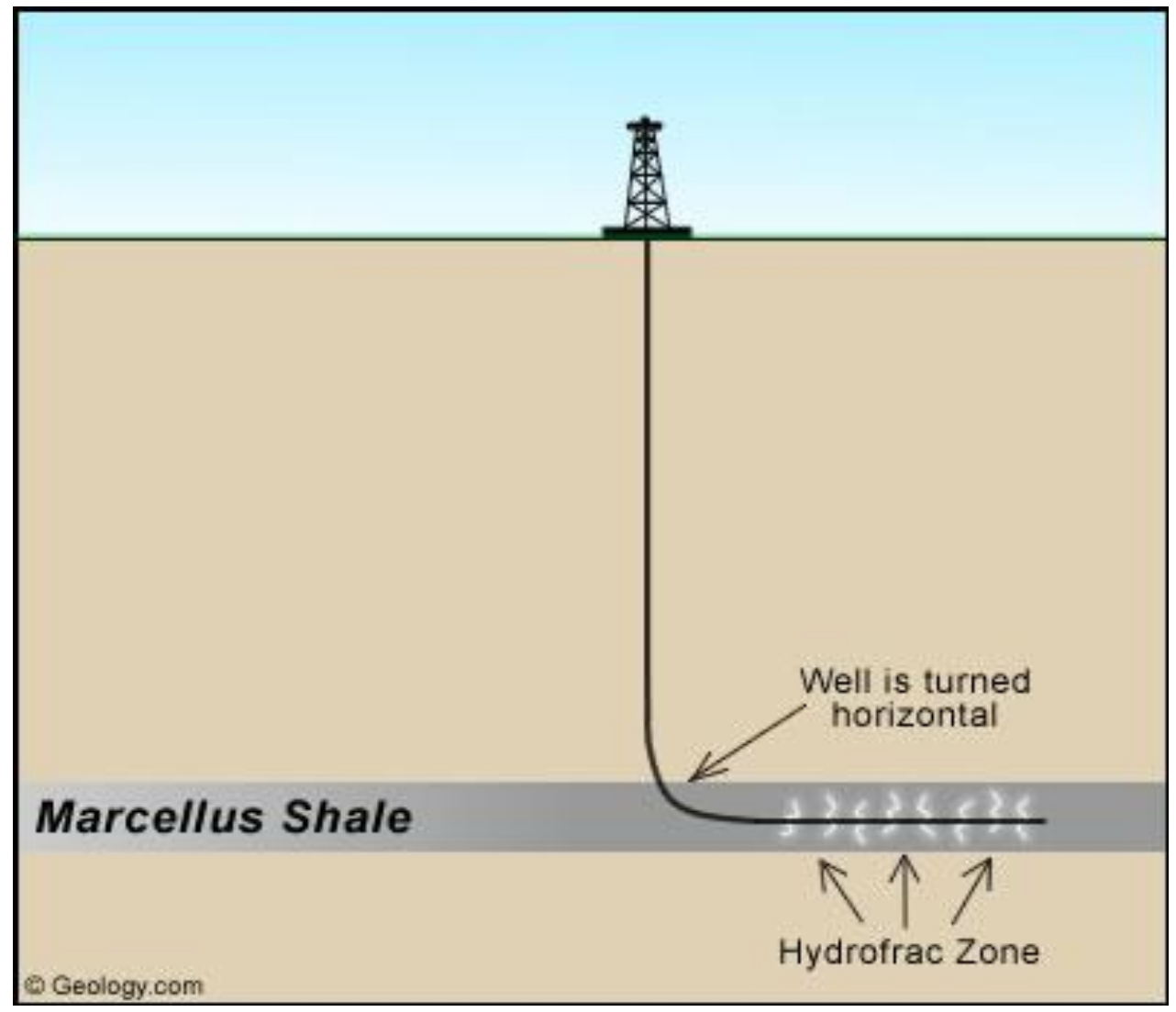

Figure 5. Horizontal well with multi stage fractures [www.geology.com] 


\subsection{Problem Statement}

It is difficult to reliably predict ultimate recovery and production rates for shale gas reservoirs, leading to great risk in exploitation of these resources. The objectives of the research are to evaluate the current decline curve analysis methods and provide a more reliable method for production forecasting and reserve estimation for hydraulically fractured horizontal wells producing from shale gas reservoirs. 


\section{CHAPTER 2}

\section{LITERATURE REVIEW}

\subsection{Decline Curve Analysis}

Decline Curve analysis is the most widely used graphical method in the industry for estimating future production of oil and gas wells. The procedure is based on finding a trend between the production history of the well and production time by plotting production history versus time. The trend is called the production decline curve of the well which by extrapolating gives the most economic forecast for future production of considering the well's economic limits. One must note that in order to have a reliable trend it is mandatory to have a long enough production history. It should be noted that decline curve approach is used for estimating recoverable hydrocarbons which are influenced by operating conditions and it cannot estimate Hydrocarbons-in-place that is fixed by the reservoir nature.

Decline Curve analysis proposed by Arp's (1945) based on empirical observations made on production decline histories different wells. Arp's identified three types of decline curves: exponential, hyperbolic, and harmonic. Because of this empirical nature, different types of decline curves must be used wisely for any particular condition the well is producing in, in single or multi-phase fluid flow. In the other words the well may show different types of decline curves during the production history depending on whether the analysis is conducted on one fluid or on the total fluids (gas, oil, oil \& water, WOR, WGR etc.) as the producing conditions may vary as the time passes. 
In order to have the most accurate decline curve there is an implicit assumption that must be guaranteed, both reservoir conditions and operating conditions causing the historical decline must remain unchanged during the forecast period. If any of the mentioned factors changes then the decline curve developed for the previous condition is not applicable for the new condition any more.

Another important point that must be considered while using Decline Curve analysis is that the production history must be from the time that the reservoir is under the stabilized flow condition when the reservoir boundaries have been fully reached and we have a constant drainage area. Thus, for the shale and tight gas reservoir that reaching the stabilization takes several years' traditional decline curve methods mentioned before are not applicable since the production histories are mostly during the transition period.

\subsection{Loss Ratio}

Decline Curve theory starts from the definition of the loss-ratio equation introducing the current decline rate parameter " $\mathrm{D}$ " which is the defined as "the fractional change in rate per unit time" [www.fekete.com]. " $\mathrm{D}$ " is usually expressed as “\% per year".

$$
\frac{1}{\mathbf{D}}=-\frac{\mathbf{q}}{\mathbf{d q} / \mathbf{d t}} \quad \text { Eq. } 1
$$

Where $\mathrm{q}$ is the rate of production and $\mathrm{t}$ is the time of production. 


\subsection{Types of Decline Curves}

Based on whether D is constant of not three different types of decline curves are defined.

- Exponential Decline: this type of decline occurs when D is constant. This method is usually used when we have a single phase, incompressible fluid production from a closed reservoir. For example Single-phase liquid production, high-pressure gas, tubing-restricted gas production, and poor waterflood performance lead to Exponential Decline.

$$
\frac{q(t)}{q_{i}}=\frac{1}{e^{D t}} \quad \text { Eq.2 }
$$

Where $\mathrm{q}_{\mathrm{i}}$ is the initial production rate $\mathrm{q}(\mathrm{t})$ is production rate with time

- Hyperbolic Decline: when the decline rate " $D$ " is not constant we need to define a new parameter decline exponent "b" which is a function of time to relate D and production rate. Based on observations in some of the production declines D varies with rate changes raised to the power of $b$. These types of decline curves are called hyperbolic decline.

$$
\frac{q(t)}{q_{i}}=\frac{1}{\left(1+b D_{i} t\right)^{1 / b}} \quad \text { Eq.3 }
$$

Where $D_{i}$ is the decline rate at flow rate $\mathrm{q}_{\mathrm{i}}$, and $\mathrm{b}$ is an exponent that varies from 0 to 1 for a stabilized flow in hyperbolic decline. 
Occasionally, decline curves with values of $b>1$ are observed. In this case either the interpretation is wrong and there would be another value of $b<1$ to fit the curve or the date set is from the transient time and the flow has not yet reached the "boundary dominated flow" or in another world the production flow is not stabilized yet.

- Harmonic Decline: This is a special case of hyperbolic decline when b equals to zero. In this case decline rate " $D$ " changes proportional to q meaning that as the $q$ tends to be zero $\mathrm{D}$ will be zero too. This type of decline usually happens when a very effective type of recovery method is being developed.

$$
\frac{q(t)}{q_{i}}=\frac{1}{\left(1+D_{i} t\right)} \quad \text { Eq.3 }
$$

The unfavorable point about this type of decline is that as the reservoir continues producing for a long time the harmonic decline curve will become a flat line and the rate will never reach zero, so we cannot determine the ultimate recoverable reserves at the abandonment rate of zero. 


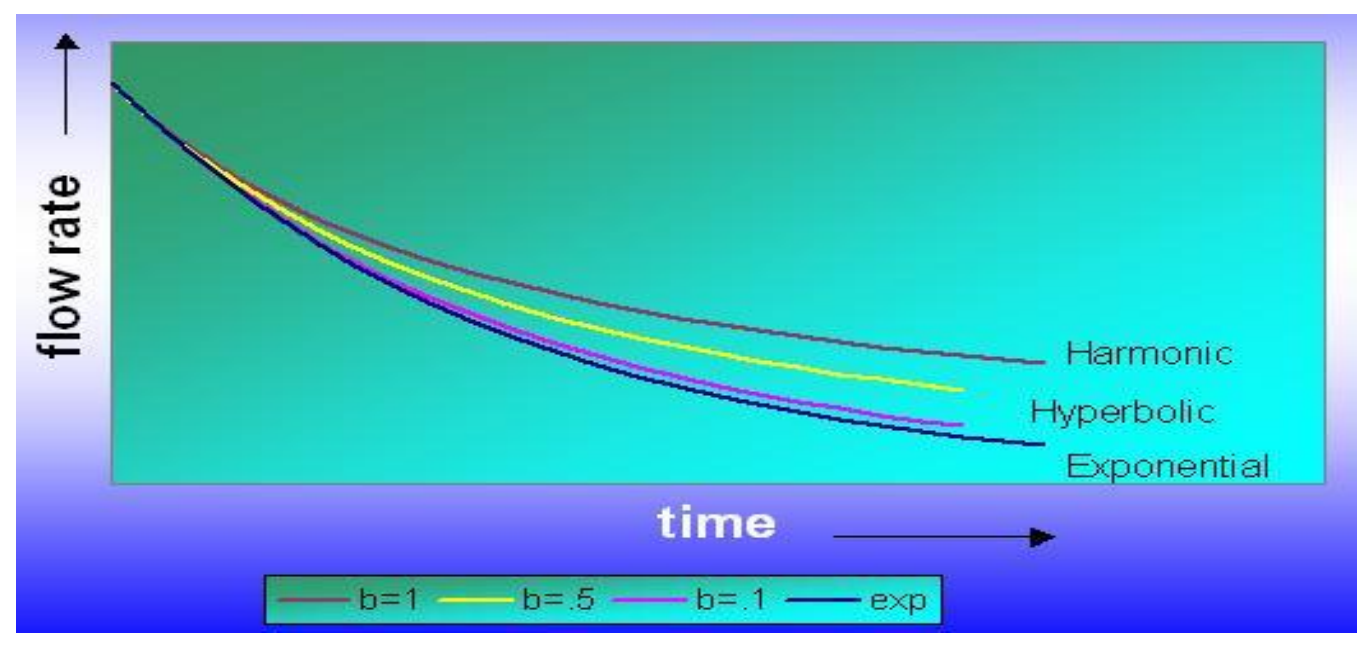

Figure 6. Different types of Decline Curves [www.fekete.com]

\begin{tabular}{|c|c|}
\hline Case & Rate Relation \\
\hline $\begin{array}{l}\text { Exponential: } \\
(b=0)\end{array}$ & 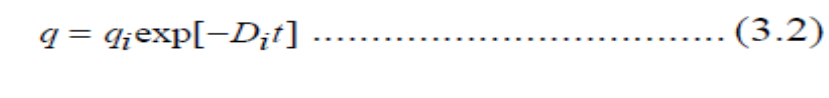 \\
\hline $\begin{array}{l}\text { Hyperbolic: } \\
(0<b<1)\end{array}$ & $q=\frac{q_{i}}{\left(1+b D_{i} t\right)^{(1 / b)}}$ \\
\hline $\begin{array}{l}\text { Harmonic: } \\
(b=1)\end{array}$ & $q=\frac{q_{i}}{\left(1+D_{i} t\right)}$ \\
\hline \multicolumn{2}{|c|}{ Arps $G_{p}$ Relations: (Blasingame and Rushing 2005) } \\
\hline Case & Cumulative Relation \\
\hline $\begin{array}{l}\text { Exponential: } \\
(b=0)\end{array}$ & 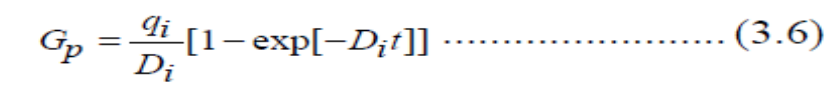 \\
\hline $\begin{array}{l}\text { Hyperbolic: } \\
(0<b<1)\end{array}$ & $G_{p}=\frac{q_{i}}{(1-b) D_{i}}\left[1-\left(1+b D_{i} t\right)^{1-(1 / b)}\right] \ldots \ldots(3.7)$ \\
\hline $\begin{array}{l}\text { Harmonic: } \\
(b=1)\end{array}$ & 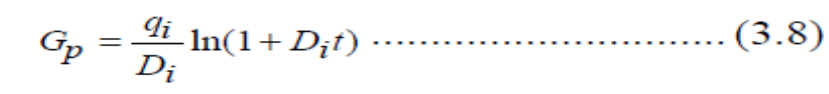 \\
\hline
\end{tabular}

Figure 7. Arps' rate-time and cumulative-time relations (adapted from Blasingame and Rushing 2005). 


\subsection{Power Law}

Arps [1945] defined the "Loss-Ratio" and the "derivative of Loss-Ratio" functions as:

$$
\text { Loss-Ratio } \frac{1}{\mathrm{D}}=-\frac{\mathrm{q}}{\mathrm{dq} / \mathrm{dt}} \quad \text { Eq.4 }
$$

$$
\text { Derivative of Loss-Ratio } \quad \mathrm{b}=\frac{\mathrm{d}}{\mathrm{dt}}\left(\frac{1}{\mathrm{D}}\right)=-\frac{\mathrm{d}}{\mathrm{dt}}\left(\frac{\mathrm{q}}{\mathrm{dq} / \mathrm{dt}}\right) \quad \text { Eq.5 }
$$

Ilk [2008 a] presented the following equations to show that the dependency on time can be

eliminated while $\mathrm{D}$ and $\mathrm{b}$ parameters:

$$
\begin{aligned}
& \mathrm{D}=-\frac{\mathrm{dq}}{\mathrm{dQ}} \\
& \mathrm{b}=\mathrm{q} \frac{\mathrm{d}}{\mathrm{dQ}}\left(\frac{1}{\mathrm{D}}\right)
\end{aligned}
$$

Where $\mathrm{Q}$ is the cumulative production rate. 
For shale and tight gas reservoirs, since it takes several years to reach the boundary dominated flow most of the data sets we have to work on are for transient time. In this case we cannot use the hyperbolic decline to analyze the future performance of the reservoirs as the main condition to use the decline curve method "the data set must be for the stabilized flow time" is not satisfied.

The best fitted values for decline exponent in harmonic decline for shale reservoirs are greater than 1 .Which is more than the limit condition mentioned by Arp's. To have a $b>1$ means cumulative production is increasing without any limitation as time increases which is physically unacceptable and will lead to over-prediction of results. However if we could have our data set from the stabilized flow we would have the best fitted decline exponent to be less than 1 .

Another point to be considered is that the hyperbolic model is based on assuming a constant b-value. However, according to observations many reasons like multilayer reservoirs, low permeability and heterogeneity in reservoirs cause the contacted-gas-in-place increase with time, which leads to non-hyperbolic behavior.

In order to solve this problem another decline curve method has been proposed by Ilk et al. [2008 a] called Power Law introducing a different function to calculate decline rate "D".

$$
\mathrm{D}=\mathrm{D}_{\infty}+\mathrm{D}_{1} \mathrm{t}-(1-\mathrm{n}) \quad \text { Eq.8 }
$$


Where " $\mathrm{D}_{1}$ "is decline constant intercept at $\mathrm{t}=1$ day, " $\mathrm{D}_{\infty}$ " is decline constant as " $\mathrm{t}$ " approaches infinity which controls the late time behavior showing stabilized flow behavior. Thus, if the reservoir does not reach boundary dominated flow then we can omit the term $\mathrm{D}_{\infty}$ $(\mathrm{D} \infty=0)$. And " $\mathrm{n}$ "is time exponent.

The Eq.8 dictates that "b" is considered changing as a function of time.by substituting EQ.8 into Eq.6 we can obtain a function to calculate "b" at any time.

$$
\mathrm{b}=\frac{\mathrm{n}(1-\mathrm{n}) \hat{\mathrm{D}}_{\mathrm{i}}}{\left[\mathrm{n}_{\mathrm{i}}+\mathrm{D}_{\infty} \mathrm{t}^{(1-\mathrm{n})}\right]^{2}} \mathrm{t}^{-\mathrm{n}} \quad \text { Eq.9 }
$$

Where $\hat{\mathrm{D}}_{\mathrm{i}}$ is decline constant and defined as $\quad \hat{\mathrm{D}}_{\mathrm{i}}=\frac{D_{1}}{n} \quad$ Eq.10

So we can calculate $\mathrm{q}$ as a function of $\mathrm{D}$ from the equation below.

$$
q=\hat{q}_{i} \exp \left(-D_{\infty} t-\hat{D}_{i} t^{n}\right)
$$

Where $\hat{\mathrm{q}}_{\mathrm{i}}$ is rate intercept. ( $\mathrm{q}$ at $\mathrm{t}=0$ ). This definition of qi is different from definition of qi in Arps decline. 
To physically explain this equation a decaying power-law function for " $\mathrm{D}$ " is defined such that it shows a power-law behavior of Loss-Ratio at the early time scales (transient time and transition period) and becomes constant for the longer time period.

For the power law method in order to find the best fitted curve, the D $\infty$ parameter is first set to zero and then later adjusted to give the best fit during the boundary flow regime since it only shows a major effect on the late portion of the power-law equations. The parameter dominates at very large times and gives a lower bound for the forecasted reserves.

The " $\mathrm{t}$ " "parameter in the equation controls both the transient and transition flow regimes whether the well is fractured or not to obtain greatly fitted matches of the production data.

The best aspect of this method is that it is flexible enough to cover transient, transition and boundary-dominated flow and for larger times behaves as an exponential decline $\left(\mathrm{D}=\mathrm{D}_{\infty}\right)$ [Ilk et al., 2008 b].

Based on many observations made so far evaluating different decline analysis methods applied on variety of well-reservoir systems, including Dimensionless fracture conductivity change, different fracture stages and fracture half- length for predicting future performances, the Power-Law method give the most accurate result for forecasting recoverable reserves in hydraulically fractured shale reservoirs. [www.fekete.com] 


\subsection{Weibull Growth Model}

The Weibull growth curve is a generalization of the widely used Weibull distribution for modeling time-to-failure in applied engineering problems [Weibull, 1954].this model is define

as:

$$
p(t)=G_{p}=M\left[1-e^{-\left(\frac{t}{\alpha}\right) \gamma}\right] \quad \text { Eq. } 12
$$

The cumulative growth, $P(\mathrm{t})$, can be equated to cumulative gas production, $G_{\mathrm{p}}$.Carrying capacity, $M$, is the physical growth (production) limit for the system, and provides an upper bound on resource extraction - unlike the Hyperbolic model. The scale parameter, $\alpha$ is that value of time at which $(1-1 / e)$ or $63.2 \%$ of the resources have been (or will be) produced. The shape parameter, $\gamma$ describes how the rate of growth changes with time. In unconventional gas wells, $\gamma$ will typically be less than 1.Indicating that the rate of growth is declining with time.[Mishra,2012]

$$
p(t)=q=M\left(\frac{\gamma}{\alpha}\right)\left(\frac{t}{\alpha}\right) \gamma-1 e^{-\left(\frac{t}{\alpha}\right) \gamma} \quad \text { Eq.13 }
$$


In terms of parameter estimation, note that the three-parameter Weibull model is reduced to 2 unknowns if we take the ratio of production rate, $q$, and cumulative production, $G \mathrm{p}$, as the dependent variable. Nonlinear regression analysis can then be used to estimate observed $q / G \mathrm{p} v / \mathrm{s}$ time to the ratio of Eq. (13) and Eq. (12).M can be estimated from fitting the production rate data with Eq.13. [Mishra,2012]

\subsection{Gas Desorption}

One of the main factors that must be taken into the consideration for shale gas reservoirs is gas desorption .The gas desorption mechanism must be included in the production model. The Langmuir isotherm is one of the oldest and straight-forward isotherms which was developed by Irving Langmuir in 1916 to describe the relationship between the surface coverage of an adsorbed gas and the pressure of the gas above the surface at a fixed temperature [Adekoya et al., 2009 b]. It provides a useful insight into the pressure dependence of the extent of surface adsorption. Adsorption molecules of one substance become attached to the surface of another. Adsorption is different from absorption as it is a reversible process interconnected by weak attracting forces in this case, shale and natural gas. [Adekoya et al., 2009 b].

Langmuir's Equation:

$$
V(P)=\frac{V_{L} P}{P_{L}+P}
$$

$\mathrm{V}(\mathrm{P})=$ Gas Content 
$V_{L}=$ Langmuir Volume

$P_{L}=$ Langmuir Pressure

$\mathrm{P}=$ Pressure $(\mathrm{psi})$

$V_{L}$ is the maximum amount of gas that can be adsorbed on the shale at infinite pressure $P_{L}$ affects the curvature of the isotherm and corresponds to the pressure at which half of the Langmuir volume is adsorbed.

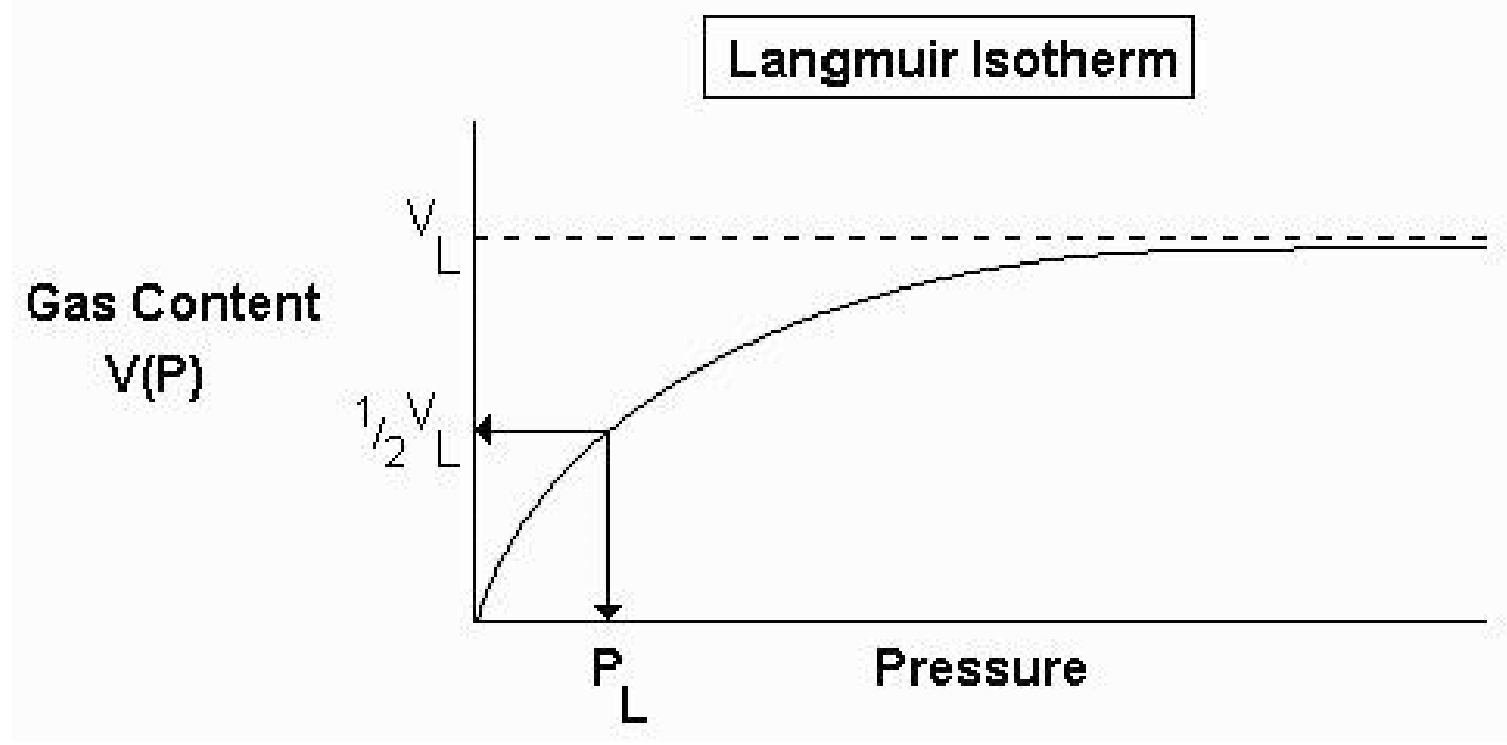

Figure 8. A Langmuir Isotherm Curve: Gas Content plotted against Pressure

[Adekoya et al 2009] 


\section{CHAPTER 3}

\section{METHODOLOGY}

3.1 Research Tasks

Literature review to determine reservoir parameters for shale gas reservoirs such as:

- Reservoir Permeability

- Reservoir Porosity

- Formation Depth and Thickness (Pay-zone)

- Reservoir Temperature

Using Schlumberger's Eclipse Software simulates a shale reservoir, considering:

- Simulation of transverse fractures in a hydraulically fractured horizontal reservoir with multistage fractures

- Use of dual porosity model (matrix and fracture systems).

- Incorporation of desorption

- Generation of data for four different reservoir-well systems.

Using four different production decline analysis methods, the following steps are to be taken;

- Perform forecast on the production data from eclipse

- Quantify errors in reserve estimates from decline analysis

- Characterize the decline behavior

- Compare all four different approaches 


\subsection{Model Parameters}

The parameters used to simulate the model are chosen from the Marcellus shale formation.

\begin{tabular}{|c|c|}
\hline \multicolumn{2}{|l|}{ Reservoir Parameters } \\
\hline Initial Reservoir Pressure, psia & 3000 \\
\hline$P_{w f}, p s i a$ & 500 \\
\hline Depth, $f t$ & 7000 \\
\hline Thickness, ft & 75 \\
\hline Fissure Porosity, fraction & 0.005 \\
\hline Matrix Porosity, fraction & 0.05 \\
\hline Fissure Permeability, $i, j, k$, md & $0.002,0.002,0.0002$ \\
\hline Matrix Permeability, $i, j, k$, md & $0.0004,0.0004,0.00004$ \\
\hline Fracture Spacing, $\sigma, 1 / \mathrm{ft}^{2}$ & 0.0073 \\
\hline Water saturation, fraction & 0.15 \\
\hline \multicolumn{2}{|l|}{ Hydraulic Fractures Properties } \\
\hline Half length, $f t$ & 500 \\
\hline Width, in & 0.01 \\
\hline Top of Fracture, $\mathrm{ft}$ & 7000 \\
\hline Bottom of Fracture, $\mathrm{ft}$ & 7075 \\
\hline Permeability, md & 2000 \\
\hline Porosity, fraction & 0.2 \\
\hline \multicolumn{2}{|l|}{ Adsorption } \\
\hline Diffusion Coefficient, $f t^{2} /$ day & 1 \\
\hline Sorption Time, day & 62 \\
\hline Langmuir Pressure, psia & 635 \\
\hline Langmuir Concentration, SCF/ton & 89 \\
\hline
\end{tabular}

Figure 9. Model Parameters [F. Belyadi, et al. 2012] 


\subsection{Flowchart of the Entire Analyzing Process}

The flowchart in Figure 19 briefly explains how methodologically the whole process was carried out starting from the collecting of data for the shale gas until the end result(estimated reserves with error analysis).

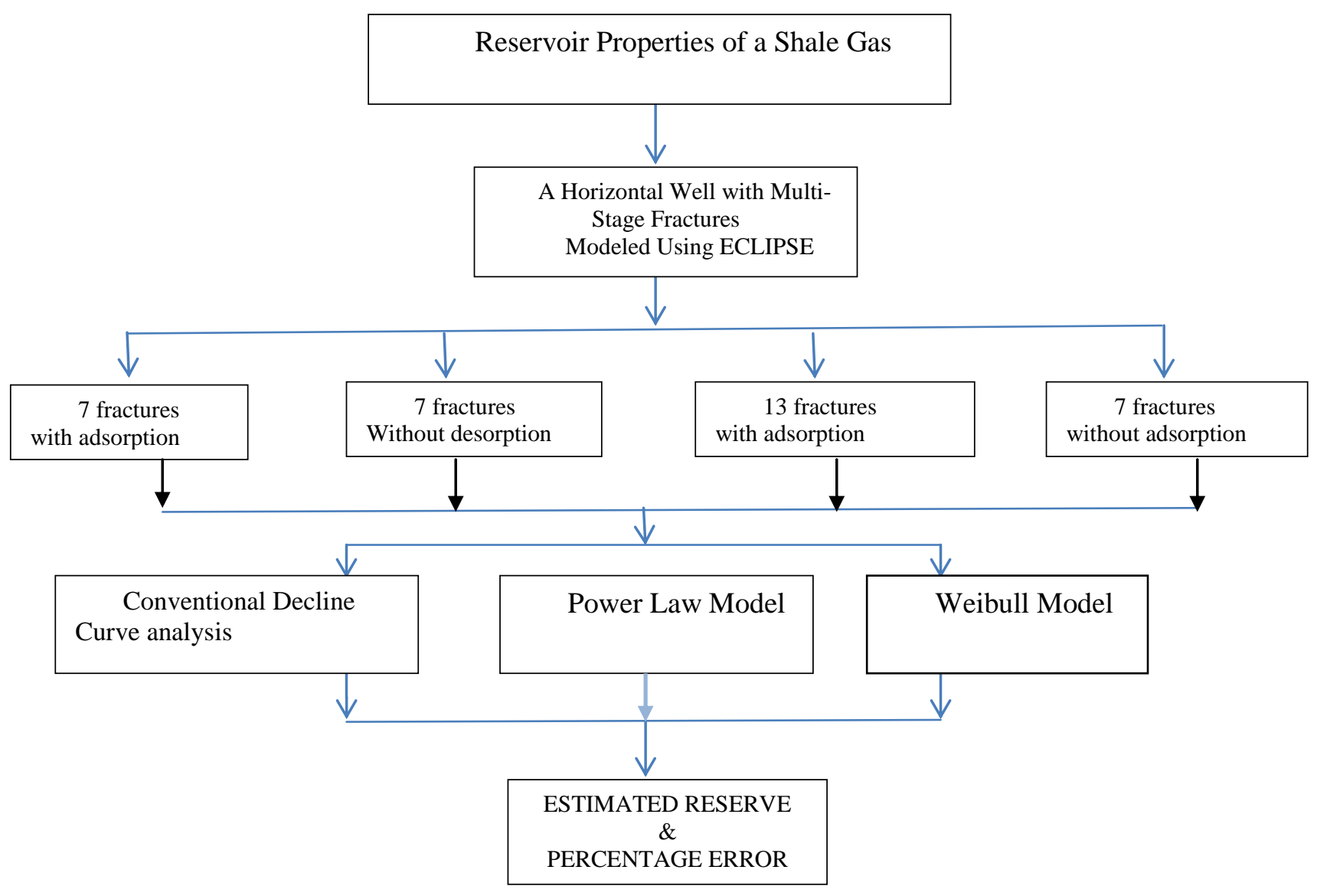

Figure 10. Flowchart of the entire analysis process. 


\section{CHAPTER 4}

\section{RESULTS AND DISCUSSIONS}

The main objective of this research is to compare two different production decline analysis methods by quantities comparison with the predicted production trends in different reservoirwell systems. It is also to develop the most reliable method to have more accurate production forecast in shale gas reservoirs. The two methods to evaluate are Power Law model and conventional decline curve analysis.

4.1 Case 1 - Horizontal well with 7 hydraulic fractures including gas adsorption

In this case, gas is produced from a horizontal well hydraulically fractured shale gas reservoir which has 7 stages of fractures including adsorbed gas. The Decline Curve analysis is performed for the first 4 years of production using power law model and conventional decline curve analysis. The production for the next16 years was then predicted based on the matched decline parameters. Finally, the predicted production history was compared against the simulated history to determine reliability of decline method predictions.

\begin{tabular}{|l|r|}
\hline \multicolumn{2}{|l|}{ Power Law } \\
\hline qi(scf/year) & 9061977 \\
\hline $\mathrm{n}$ & 0.292 \\
\hline $\mathrm{D} \infty$ & 0.00009 \\
\hline $\mathrm{Di}$ & 1.68 \\
\hline
\end{tabular}




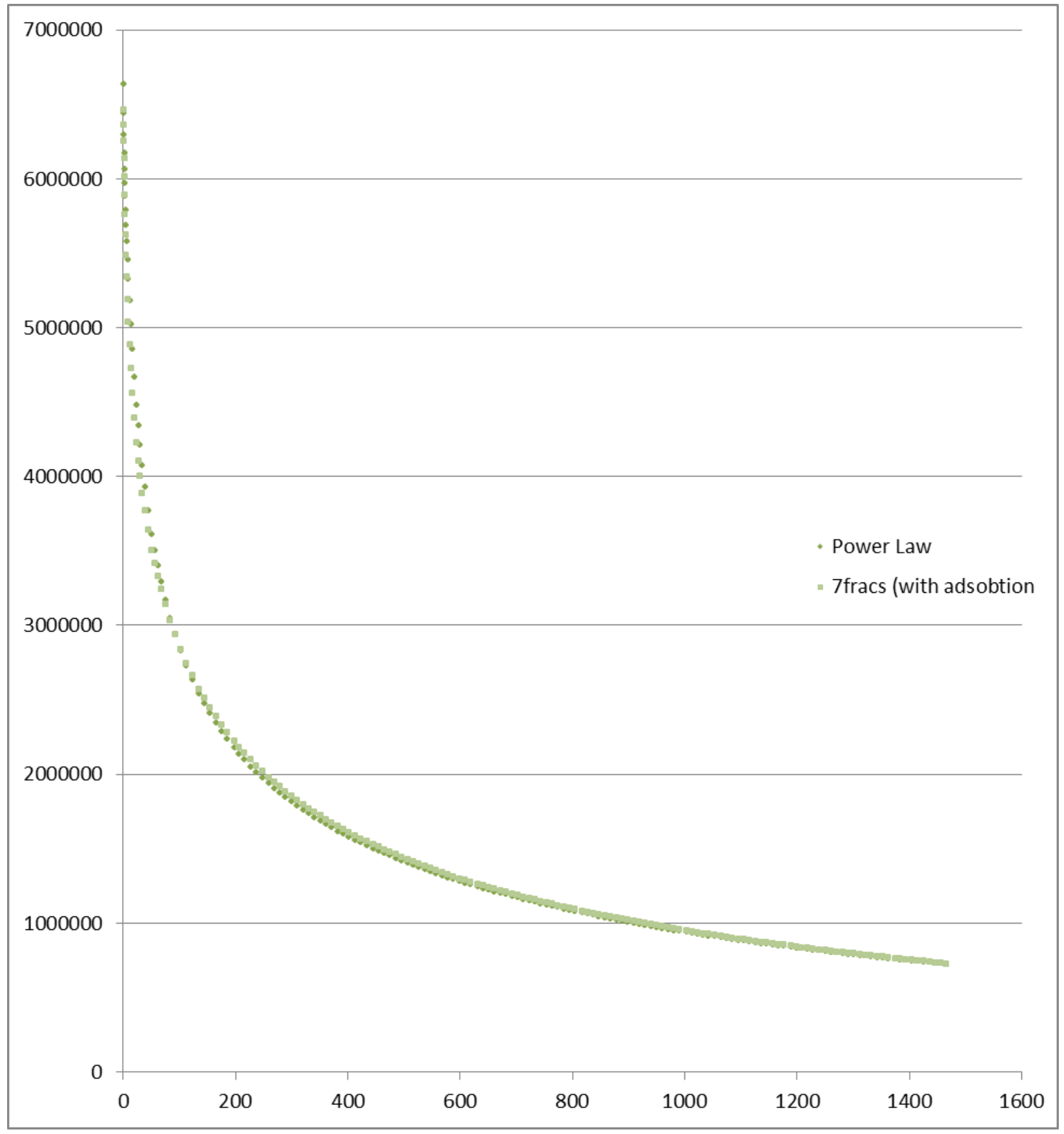

Figure 11. 7 Fractures with Adsorption, simulated data curve vs. Power Law model match 


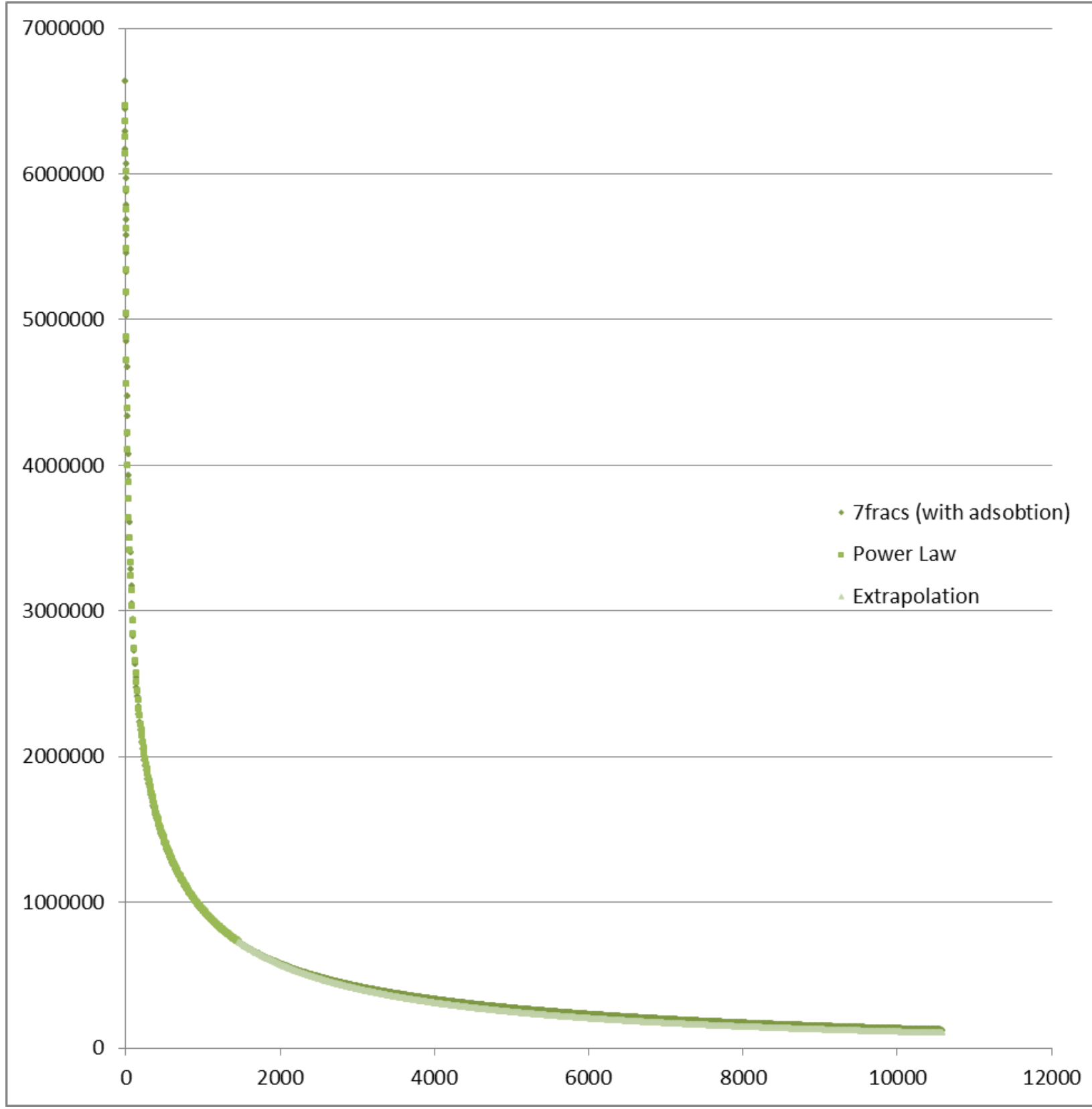

Figure 12. Extrapolation for the nest 16 years of production ( 7 fractures with adsorption) 


\begin{tabular}{|l|r|}
\hline $\begin{array}{l}\text { Conventional } \\
\text { Decline curve }\end{array}$ & \\
\hline qi(scf/year) & 6204377 \\
\hline $\mathrm{Di}$ & 0.015 \\
\hline $\mathrm{b}$ & 1.75 \\
\hline
\end{tabular}

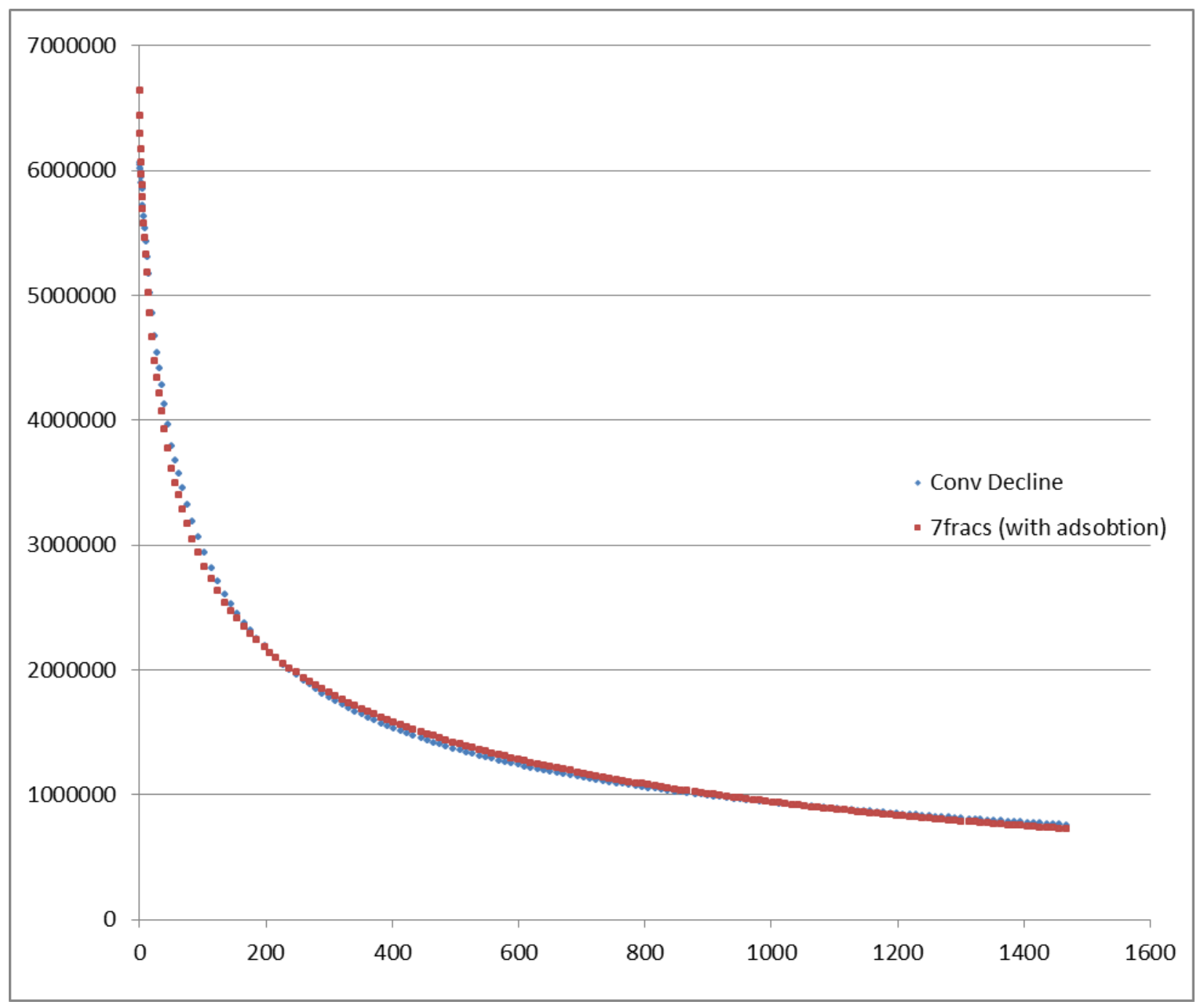

Figure 13. 7 Fractures with Adsorption, simulated data curve vs. Conventional Decline match 


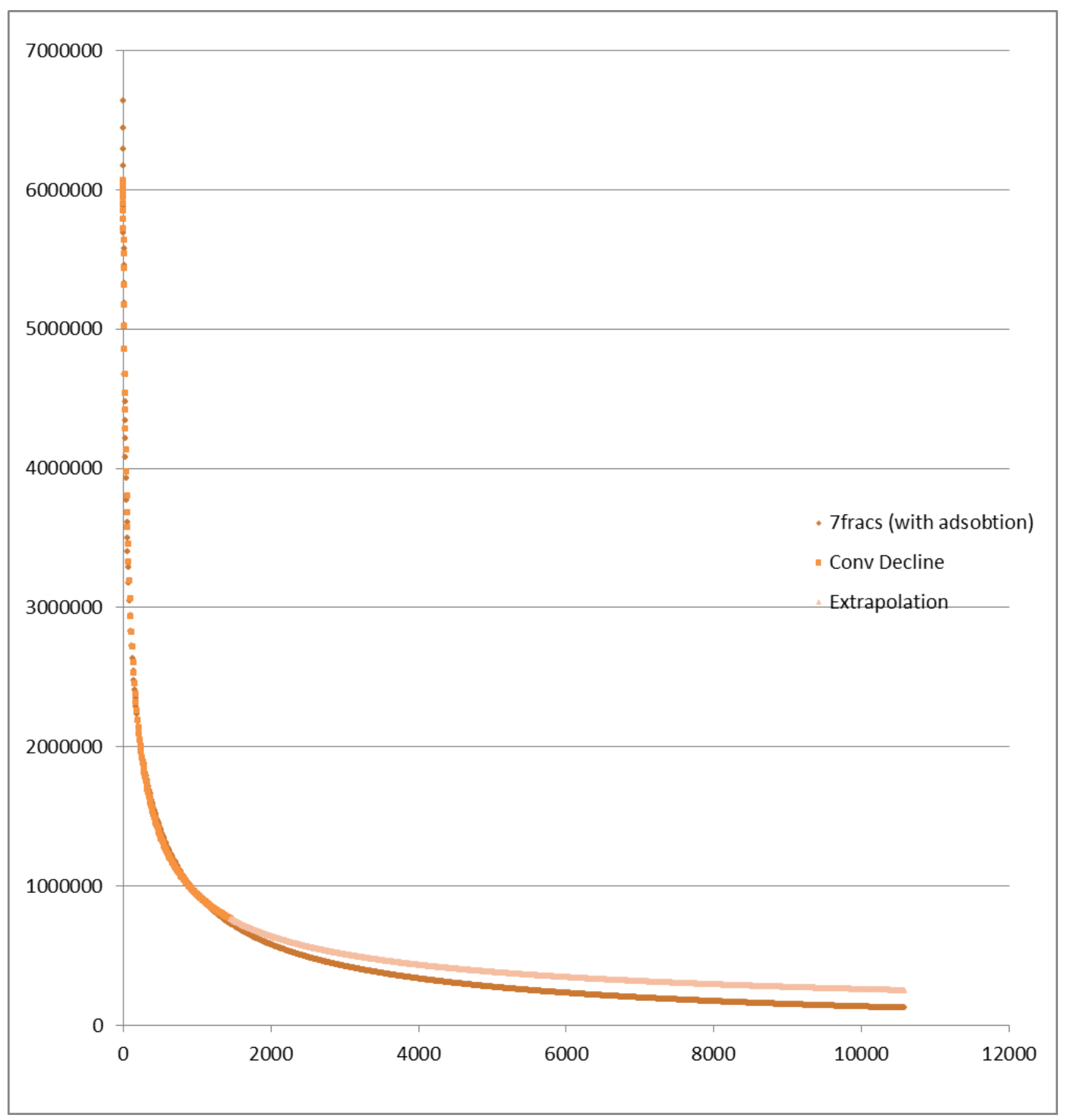

Figure 14. Extrapolation for the nest 16 years of production ( 7 fractures with adsorption) 
Comparing the results shows that for 7 fractures system with adsorption using power law model will give a better estimation for shale gas reserves rather than the conventional decline curves. based on the results Conventional Decline match over estimates the amount of reserves as time passes.

4.2 Case 2 - Horizontal well with 7 hydraulic fractures excluding gas adsorption

In this case, gas is produced from a horizontal well hydraulically fractured shale gas reservoir which has 7 stages of fractures excluding adsorbed gas. The Decline Curve analysis is performed for the first 4 years of production using power law model and conventional decline curve analysis. The production for the next16 years was then predicted based on the matched decline parameters. Finally, the predicted production history was compared against the simulated history to determine reliability of decline method predictions.

\begin{tabular}{|l|r|}
\hline \multicolumn{2}{|l|}{ Power Law } \\
\hline qi(scf/year) & 9361977 \\
\hline $\mathrm{n}$ & 0.295 \\
\hline $\mathrm{D} \infty$ & 0.00009 \\
\hline $\mathrm{Di}$ & 1.78 \\
\hline
\end{tabular}




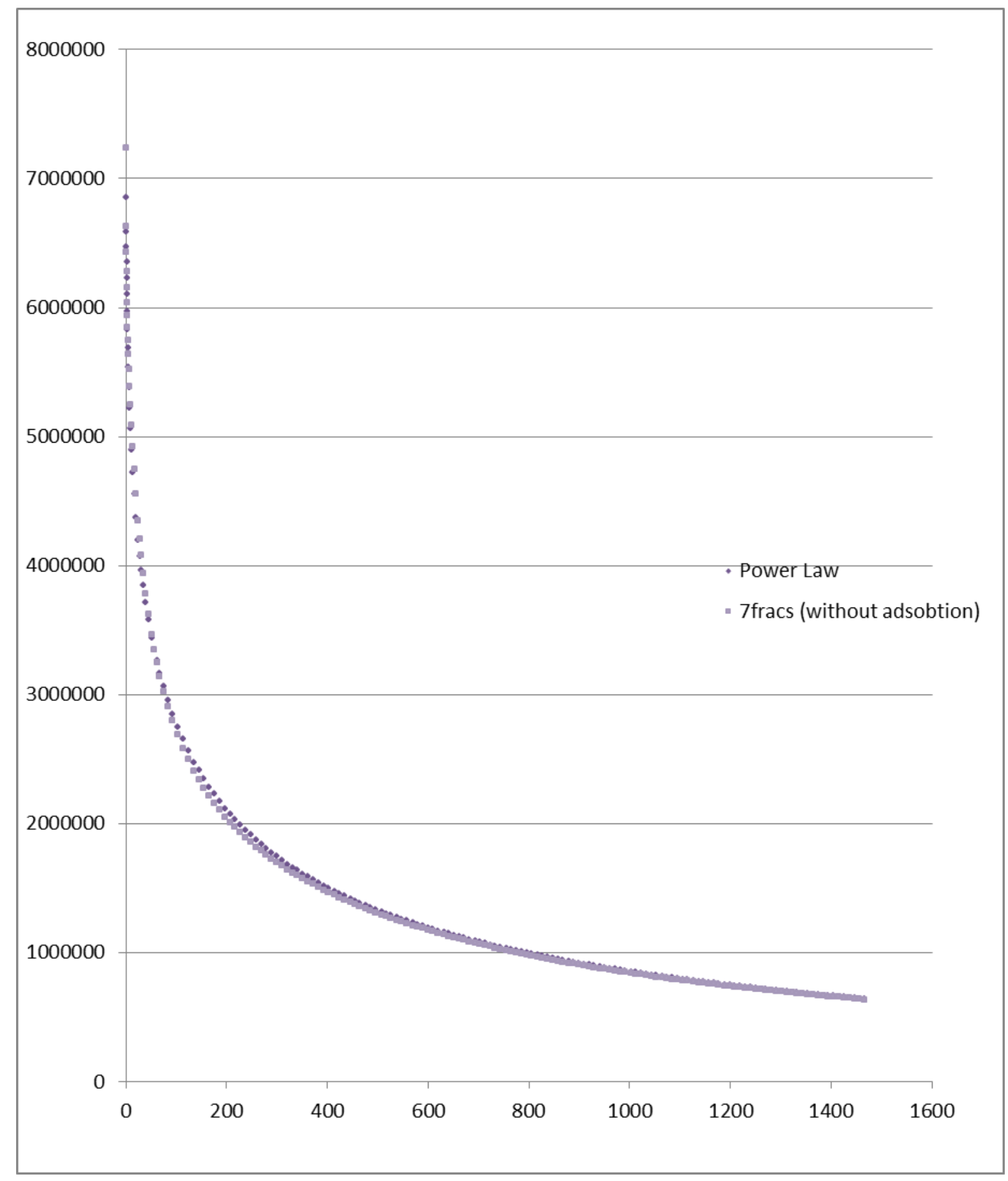

Figure 15. 7 Fractures without Adsorption, simulated data curve vs. Power Law model match 


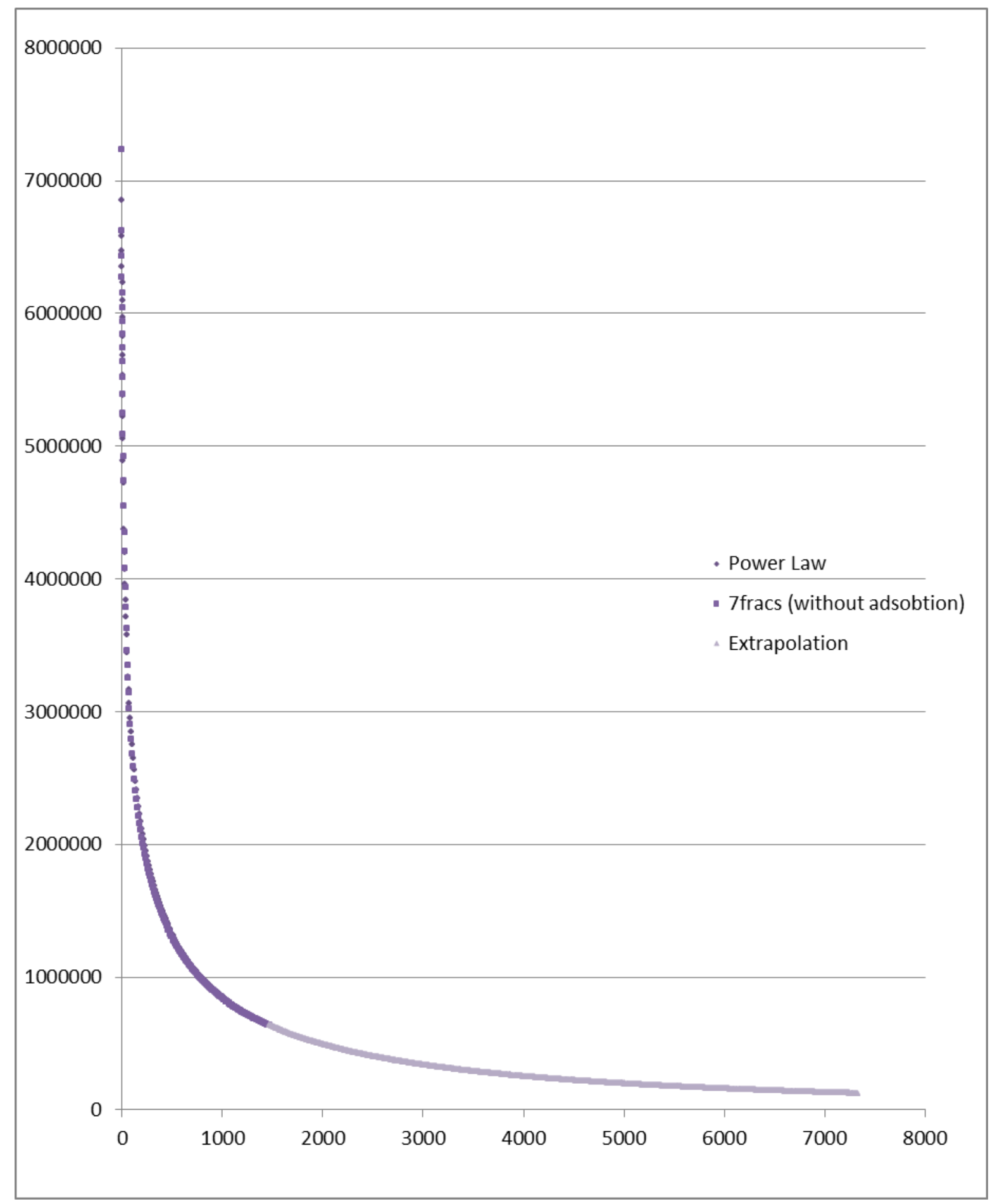

Figure 16. Extrapolation for the rest 16 years of production ( 7 fractures without adsorption) 


\begin{tabular}{|l|r|}
\hline \multicolumn{2}{|l|}{$\begin{array}{l}\text { Conventional Decline } \\
\text { Curve }\end{array}$} \\
\hline qi(scf/year) & 7204377 \\
\hline Di & 0.027 \\
\hline b & 1.76 \\
\hline
\end{tabular}

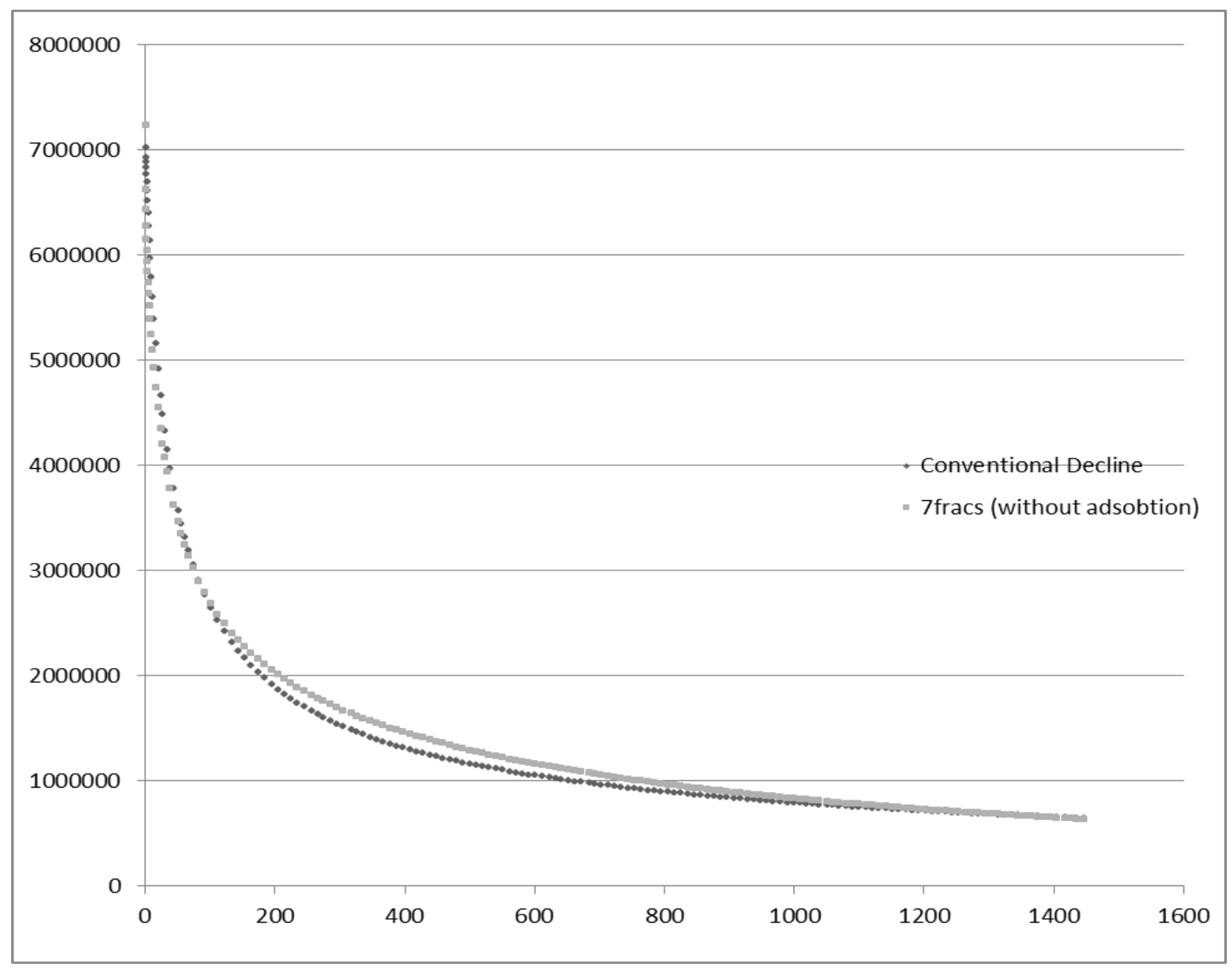

Figure 17. 7 Fractures without Adsorption, simulated data curve vs. Conventional Decline match 


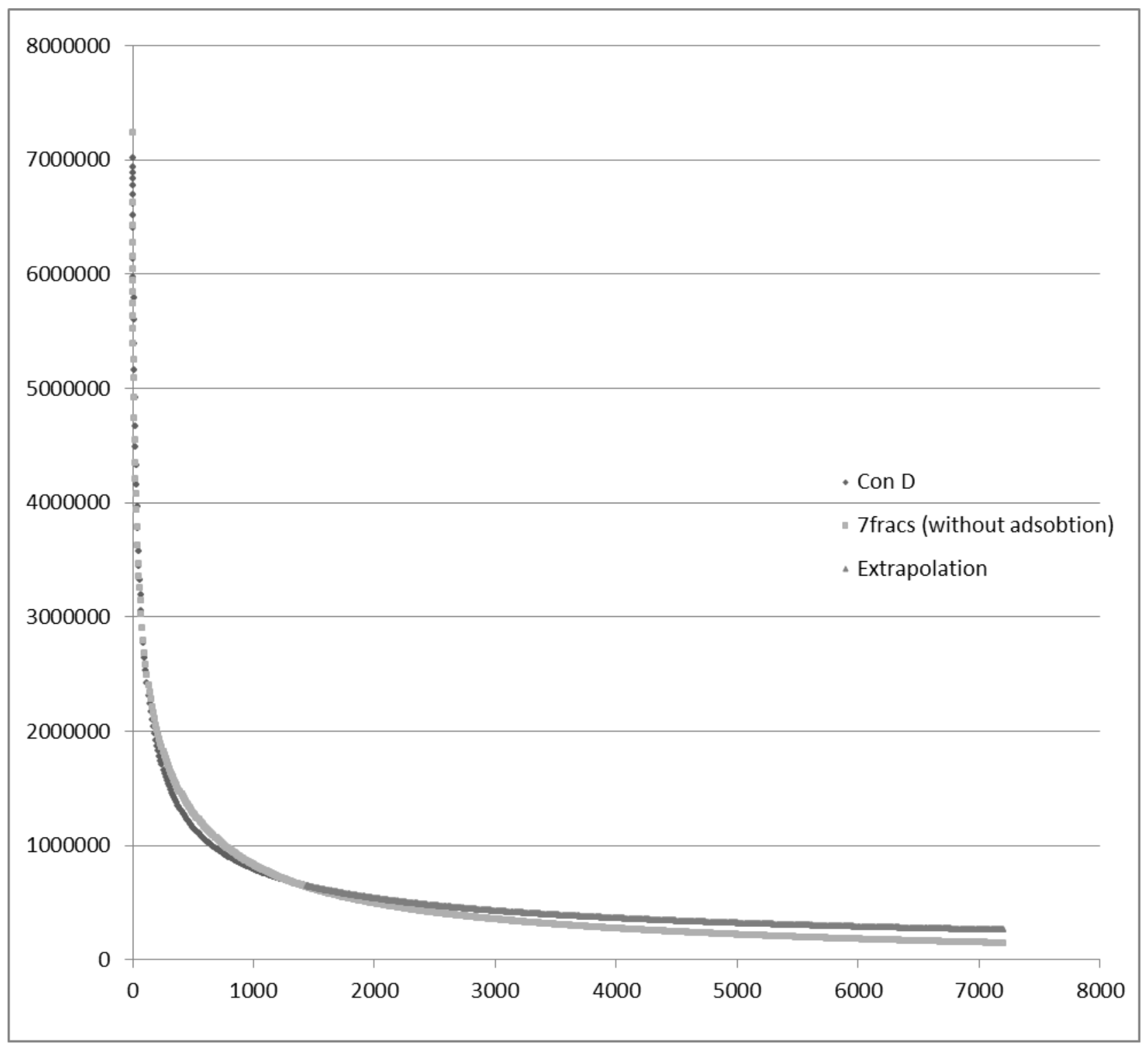

Figure 18. Extrapolation for the next 16 years of production ( 7 fractures without adsorption) 
Based on the results in case of not having adsorption using conventional decline match does not give a good match for the transition period and kind of over estimates the reserves thus Power Law decline analysis would be a better method to use as it leads to more accurate reserve estimation in shale gas reservoirs rather than the conventional decline matches.

4.3 Case 3 - Horizontal well with 13 hydraulic fractures including gas adsorption

In this case, gas is produced from a horizontal well hydraulically fractured shale gas reservoir which has 13 stages of fractures including adsorbed gas. The Decline Curve analysis is performed for the first 4 years of production using power law model and conventional decline curve analysis. The production for the next16 years was then predicted based on the matched decline parameters. Finally, the predicted production history was compared against the simulated history to determine reliability of decline method predictions.

\begin{tabular}{|l|r|}
\hline \multicolumn{2}{|l|}{ Power Law } \\
\hline qi(scf/year) & 17619771 \\
\hline $\mathrm{n}$ & 0.267 \\
\hline $\mathrm{D} \infty$ & 0.00000009 \\
\hline $\mathrm{Di}$ & 2.1 \\
\hline
\end{tabular}




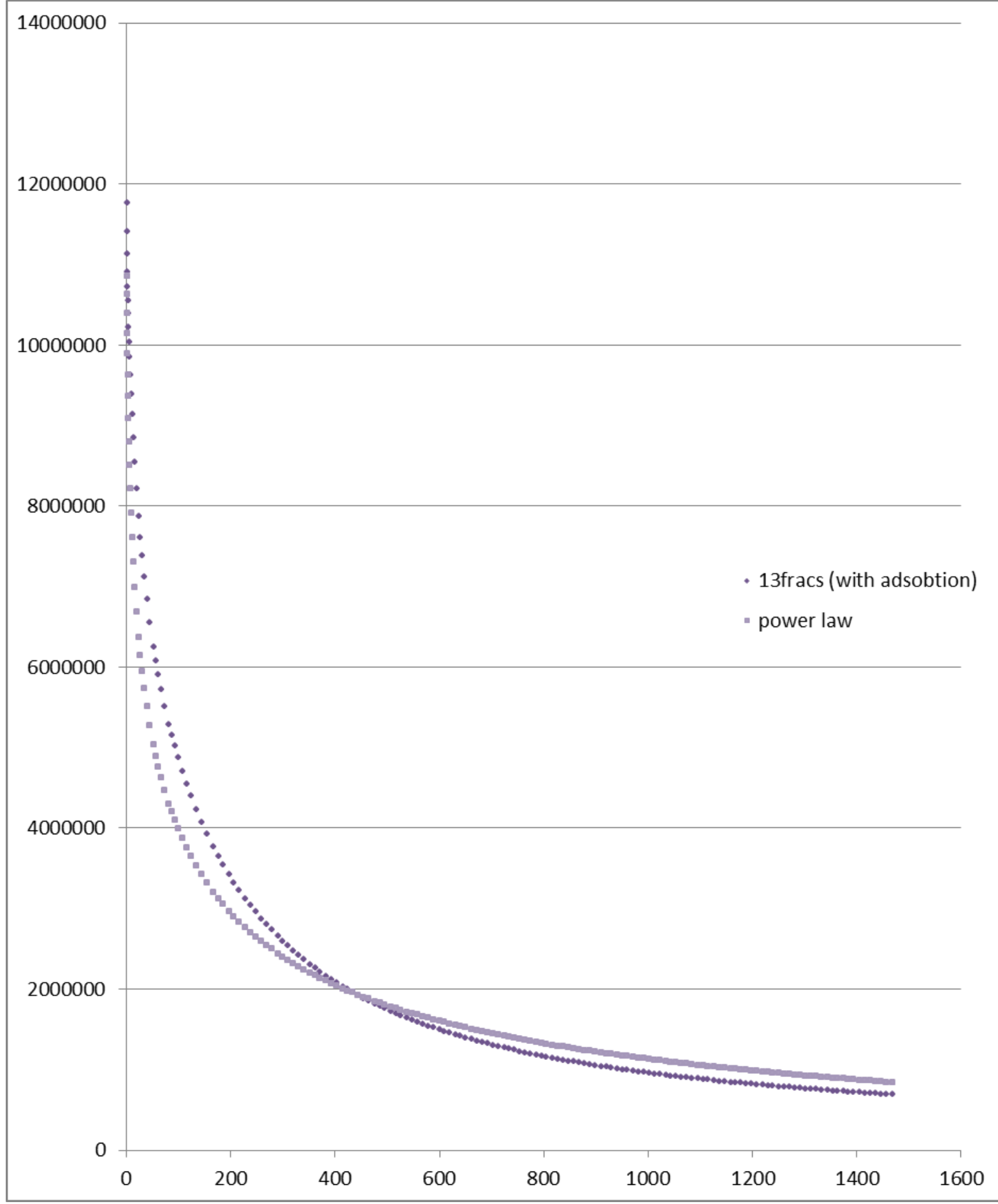

Figure 19. 13 Fractures with adsorption, simulated data curve vs. Power Law model match 


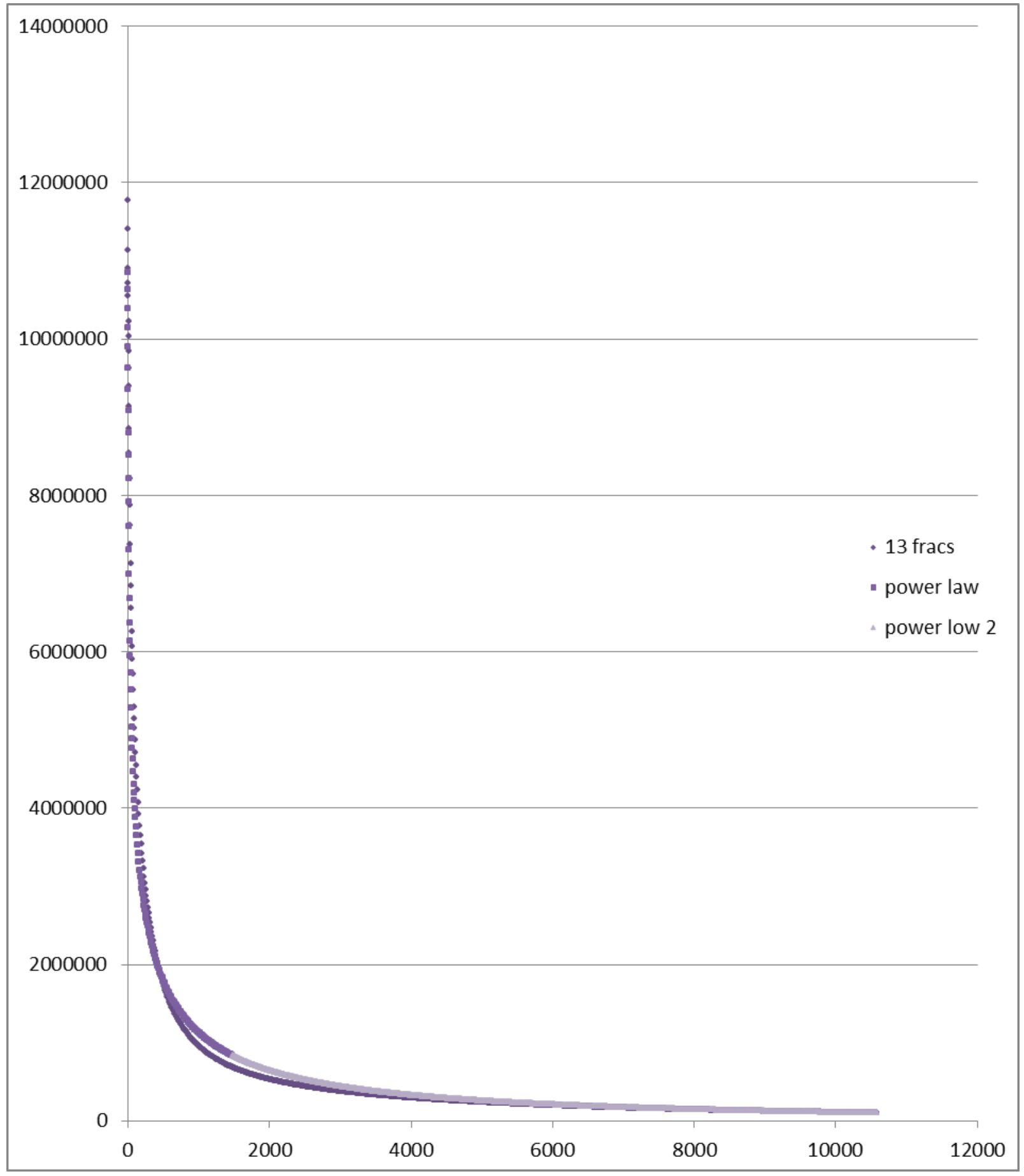

Figure 20. Extrapolation for the next 16 years of production (13 fractures with adsorption) 


\begin{tabular}{|l|r|}
\hline \multicolumn{2}{|l|}{$\begin{array}{l}\text { Conventional Decline } \\
\text { curve }\end{array}$} \\
\hline qi(scf/year) & 11834377.4 \\
\hline $\mathrm{Di}$ & 0.017 \\
\hline $\mathrm{b}$ & 1.22 \\
\hline
\end{tabular}

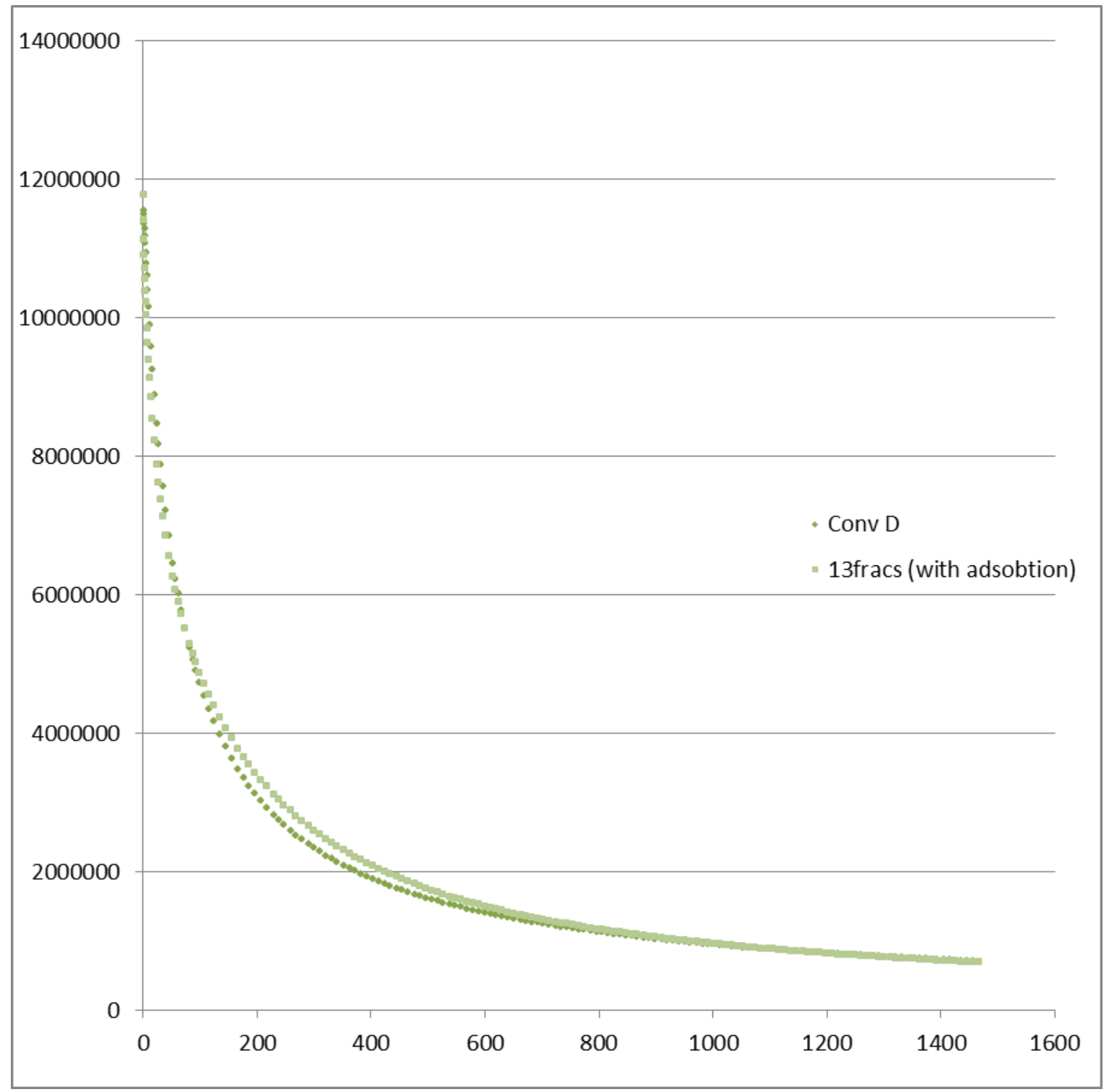

Figure 21.13 Fractures with adsorption, simulated data curve vs. Conventional Decline match 


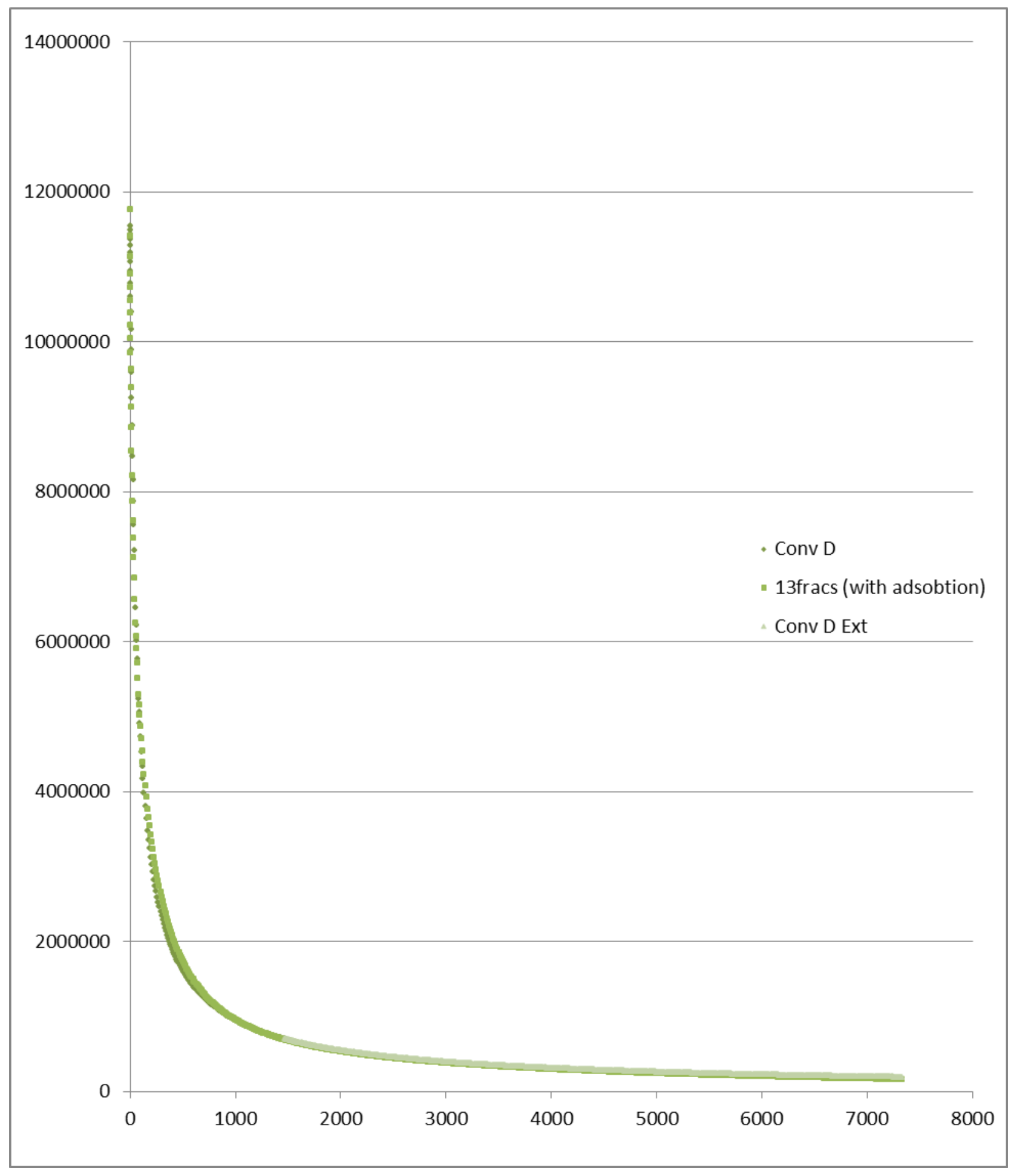

Figure 22. Extrapolation for the rest 16 years of production (13 fractures with adsorption) 
Comparison of the results indicates that the power law model cannot provide as good match during the transition period as compared to the conventional decline. Although for the year 18 and on, the errors using power law are lower than the conventional decline. The high errors for the transition period leads us to choose conventional decline curve analysis as there is a higher amounts of production during that period and high errors has significant economic implication. While, during the late production period due to low production rates even large errors do not have significant economic implication.

It appears that the power law lacks ability to predict the transition period accurately due to the increased gas desorption resulting from increased number of hydraulic fractures. Furthermore, as the number of hydraulic fractures increases the duration of transient period decreases which may also impact the accuracy of the power law model predictions.

\subsection{Case 4 - Horizontal well with 13 Fractures excluding Desorbed Gas}

In this case, gas is produced from a horizontal well hydraulically fractured shale gas reservoir which has 13 stages of fractures but the adsorbed gas is excluded from the production model (simulator). The decline curve analysis was performed for the first 4 years of production using power law model and conventional decline curve analysis. The production for the next16 years was then predicted based on the matched decline parameters. Finally, the predicted production history was compared against the simulated history to determine reliability of decline method predictions. 


\begin{tabular}{|l|r|}
\hline Power Law \\
\hline qi(scf/year) & 16861977.1 \\
\hline $\mathrm{n}$ & 0.35 \\
\hline D & 0.00009 \\
\hline Di & 2.09 \\
\hline
\end{tabular}

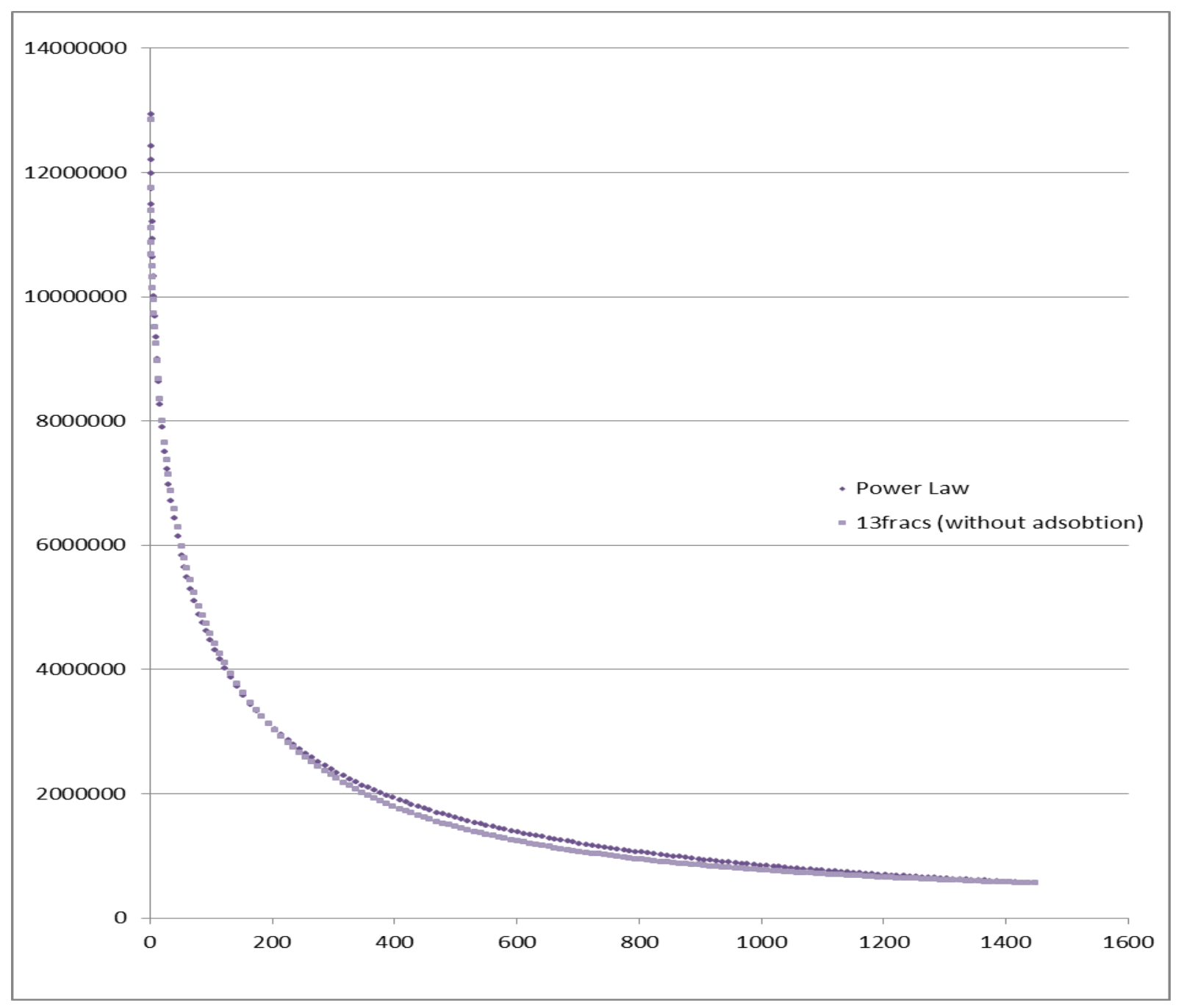

Figure 23. 13 Fractures without adsorption, simulated data curve vs. Power Law match 


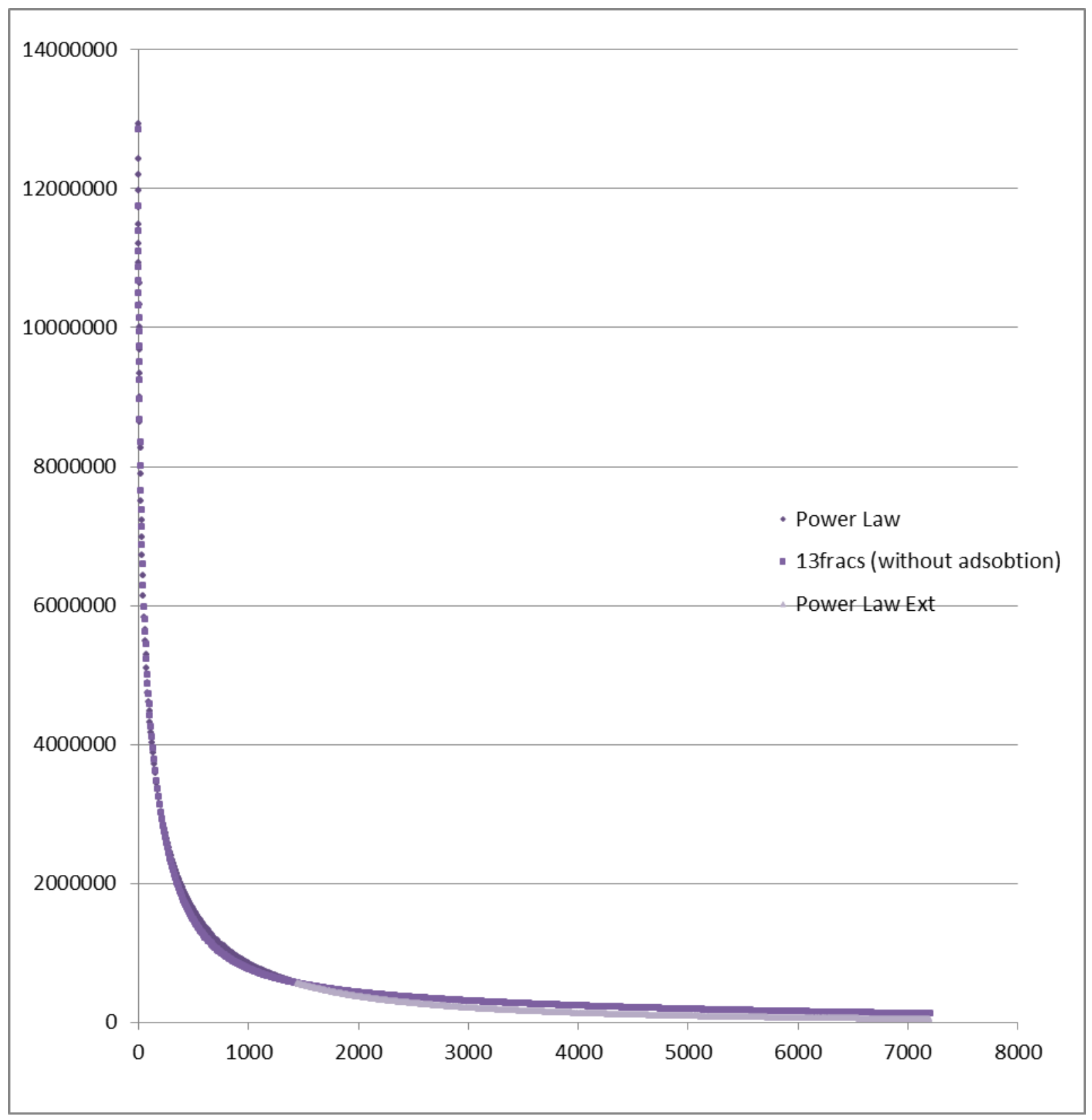

Figure 24. Extrapolation for the next 16 years of production (13 fractures without adsorption) 


\begin{tabular}{|l|r|}
\hline \multicolumn{2}{|l|}{ Conventional Decline Curve } \\
\hline qi(scf/year) & 12834377 \\
\hline $\mathrm{Di}$ & 0.021 \\
\hline $\mathrm{b}$ & 1.15 \\
\hline
\end{tabular}

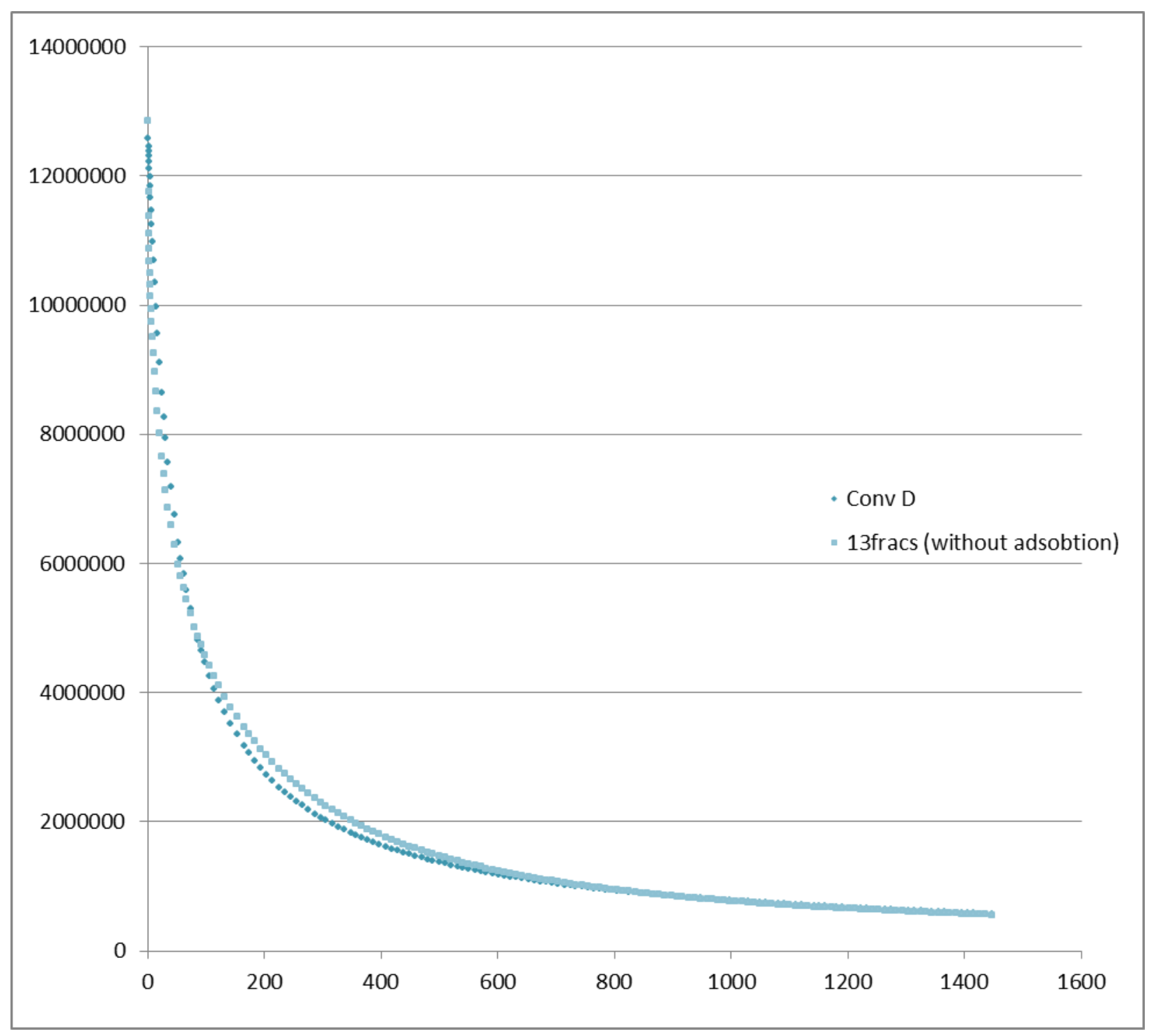

Figure 25. 13 Fractures without adsorption, simulated data curve vs. Conventional Decline match 


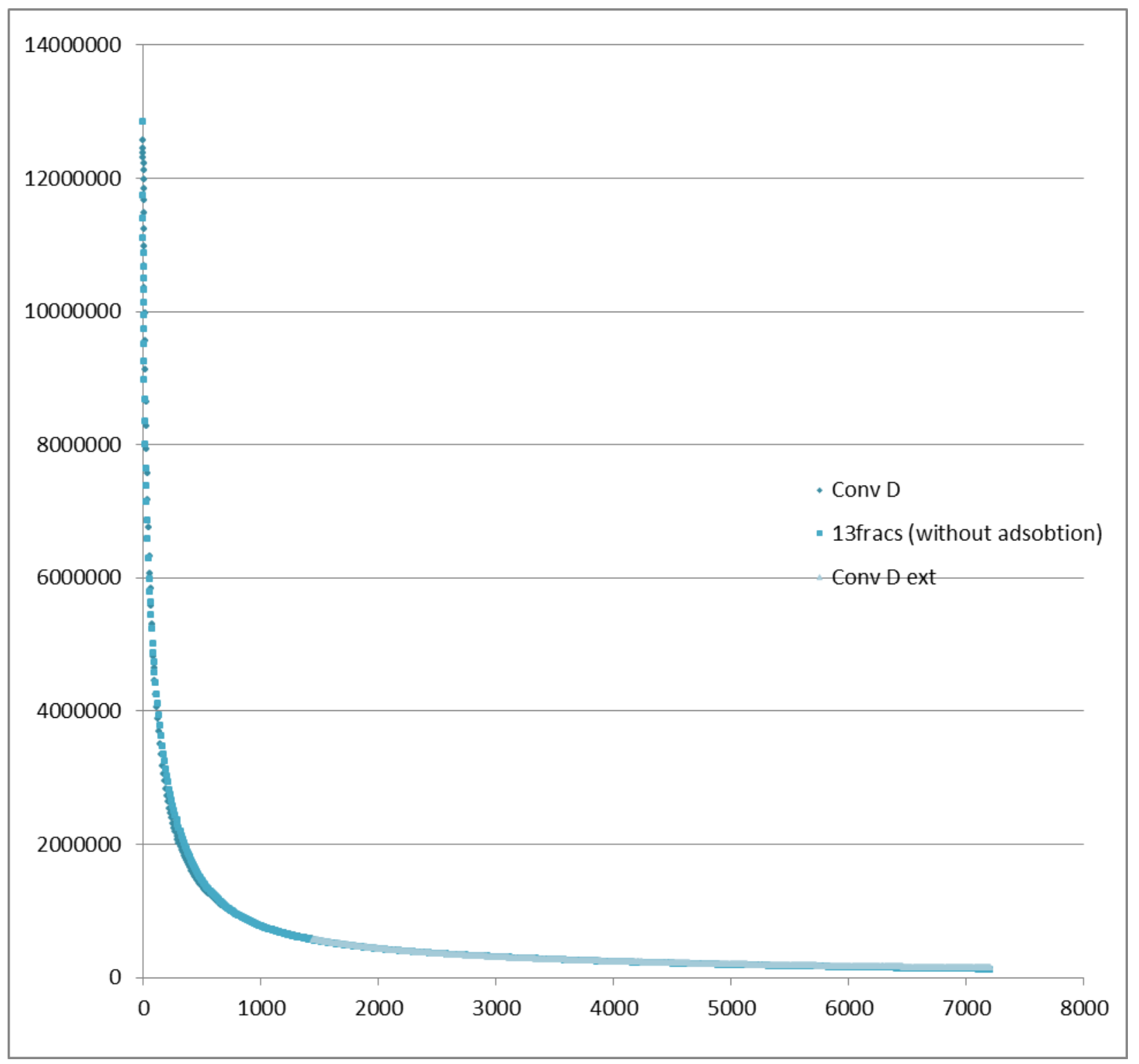

Figure 26. Extrapolation for the rest 16 years of production (13 fractures without adsorption)

Comparing the results shows that the power law model cannot really give a good match for the transition period comparing to the conventional decline match. 


\section{CHAPTER 5}

\section{SUMMERY AND CONCLUSION}

The results of this research study shows that power law model, which has been proposed for unconventional reservoirs, provides accurate and reliable estimates of the future production rates when the number of hydraulic fractures is less than 7. However, as the number of fractures increases to 13 , the power law model was found to be less reliable for estimating future production rates and ultimate recovery. Although the conventional decline method is not theoretically correct for predicting the future production rates when the transient flow impacts the production rates, it could provide more reliable predictions than the power law model when the number of fractures is more than 7. Weibull model was also considered in this study and was found to be incapable of matching the production history.

This Research would recommend using the power law model to estimate ultimate recovery for reservoirs without adsorbed gas and also reservoirs with adsorbed gas which there are less than 7 fracture stages in their well system. It also recommends using conventional decline curve analysis to forecast future production of the reservoirs without adsorbed gas and also with adsorbed gas which have more than 7 fracture stages in their well system. 


\section{REFERENCES}

A. S. BOULIS,D. ILK,T. A. BLASINGAME. (2009). A New Series of Rate Decline Relations Based on the Diagnosis of Rate-Time Data. Canadian International Petroleum Conference (CIPC). Calgary, Alberta, Canada: Petroleum Society journals.

Adam M. Lewis and Richard G. Hughes. (2008). Production Data Analysis of Shale Gas Reservoirs. SPE Annual Technical Conference and Exhibition 116688. Denver, Colorado: SPE Society of Petroleum Engineers.

Adekoya, F. (2009). PRODUCTION DECLINE ANALYSIS OF HORIZONTAL WELL IN GAS SHALE. Morgantown, West Virginia, U.S.A.

Bachman, B. (2011). Production Forecasting for Deserves Determination. Calgary SPE Technical Luncheon. Calgary, Alberta, Canada. Retrieved from www.TaurusRS.com

Brigham, W. E. (1997, June ). Water Influx, and Its Effect on Oil Recovery:Part 1. Aquifer Flow. Stanford, California.

CAMPOS, M. D. (n.d.). UNCERTAINTIES IN SHALE GAS IN-PLACE CALCULATIONS: MOLECULAR SIMULATION APPROACH. Norman, Oklahoma.

Dilhan ILK,Tom BLASINGAME. (2009). Well Performance Analysis — Low to Ultra-Low Permeability Reservoirs. SPE Mid-Continent Section. Tulsa, OK: SPE.

Engelder, T. (n.d.). Gas Decline Curves in the Marcellus Shale Play. Pennsylvania. 
L. Matter, B. Gault, K. Morad, C. M. freeman, D. IIK, and T. A Blasingame. (2008). Production Analysis and Forecasting of Shale Gas Reservoirs: Case HIstory-Base Approach. SPE Shale Gas Production Conference. Forth Worth, Teas: Society of Petroleum Enginners 119897.

Lewis, A. M. (2007, December). PRODUCTION DATA ANALYSIS OF SHALE GAS RESERVOIRS. Louisiana.

R. Strickland, D. Purvis, and T. Blasingame, SPE. (2011). Practical Aspects of Reserve Determinations for Shale Gas. SPE North American Unconventional Gas Conference and Exhibition. Woodlands, Texas: Society of Petroleum Engineers.

Ray Ambrose, Robert Hartman,Mery Diaz-Campos, I. Yucel Akkutly, Carl H. Sondergeld. (2010). New Pore-scale Considerations for Shale Gas in Place Calculations. SPE Unconventional Gas Conference. Pittsburgh, Pennsylvania, USA: Society of Petroleum Engineers Language.

Ray J. Ambrose,C.R Claskson, Jerry Youngblood, Rod Adams; and Phung Nguyen; M. Nobakht; Brent Biseda. (2011). Life-Cycle Decline Curve Estimation for Tight/Shale Gas Reservoirs. SPE Hydraulic Fracturing Technology Conference and Exhibition. Woodlands, Texas: Society of Petroleum Engineers 140519. 
Stuart A. Cox, John V. Gilbert, Robert P. Sutton, Ronald P. Stoltz. (n.d.). Reserve Analysis for Tight Gas. SPE Eastern Regional Meeting (p. 2002). Lexington, Kentucky: Society of Petroleum Engineers 78695.

Srikanta Mish. A New Approach to Reserve Estimation in Shale Gas Reservoirs Using Multiple Decline Curve Analysis Models. SPE Eastern Regional Meeting (p. 2012). Lexington, Kentucky: Society of Petroleum Engineers 161092.

F. Belyadi, A. Mashayekhi, K. Aminian, and S. Ameri Production Performance of the Hydraulically Fractured Horizontal Wells. SPE Eastern Regional Meeting. Lexington, Kentucky: Society of Petroleum Engineers 16348.

www.geology.com

www.fekete.com 